Boston University School of Law

Scholarly Commons at Boston University School of Law

Faculty Scholarship

2007

\title{
Antitrust Around the World: An Empirical Analysis of the Scope of Competition Laws and Their Effects
}

\author{
Keith N. Hylton \\ Boston University School of Law \\ Fei Deng \\ National Economic Research Associates
}

Follow this and additional works at: https://scholarship.law.bu.edu/faculty_scholarship

Part of the Antitrust and Trade Regulation Commons

\section{Recommended Citation}

Keith N. Hylton \& Fei Deng, Antitrust Around the World: An Empirical Analysis of the Scope of Competition Laws and Their Effects, in 74 Antitrust Law Journal 271 (2007).

Available at: https://scholarship.law.bu.edu/faculty_scholarship/852

This Article is brought to you for free and open access by Scholarly Commons at Boston University School of Law. It has been accepted for inclusion in Faculty Scholarship by an authorized administrator of Scholarly Commons at Boston University School of Law. For more information, please contact lawlessa@bu.edu. 


\section{HEINONLINE}

DATE DOWNLOADED: Fri Sep 9 20:26:28 2022

SOURCE: Content Downloaded from HeinOnline

Citations:

Bluebook 21st ed.

Keith N. Hylton \& Fei Deng, Antitrust around the World: An Empirical Analysis of the

Scope of Competition Laws and Their Effects, 74 Antitrust L.J. 271 (2007).

ALWD 7th ed.

Keith N. Hylton \& Fei Deng, Antitrust around the World: An Empirical Analysis of the Scope of Competition Laws and Their Effects, 74 Antitrust L.J. 271 (2007).

APA 7th ed.

Hylton, K. N., \& Deng, F. (2007). Antitrust around the world: an empirical analysis of the scope of competition laws and their effects. Antitrust Law Journal, 74(2), 271-342.

Chicago 17th ed.

Keith N. Hylton; Fei Deng, "Antitrust around the World: An Empirical Analysis of the Scope of Competition Laws and Their Effects," Antitrust Law Journal 74, no. 2 (2007): 271-342

McGill Guide 9th ed.

Keith N. Hylton \& Fei Deng, "Antitrust around the World: An Empirical Analysis of the Scope of Competition Laws and Their Effects" (2007) 74:2 Antitrust LJ 271.

AGLC 4th ed.

Keith N. Hylton and Fei Deng, 'Antitrust around the World: An Empirical Analysis of the Scope of Competition Laws and Their Effects' (2007) 74(2) Antitrust Law Journal 271

MLA 9th ed.

Hylton, Keith N., and Fei Deng. "Antitrust around the World: An Empirical Analysis of the Scope of Competition Laws and Their Effects." Antitrust Law Journal, vol. 74, no. 2, 2007, pp. 271-342. HeinOnline.

OSCOLA 4th ed.

Keith N. Hylton \& Fei Deng, 'Antitrust around the World: An Empirical Analysis of the Scope of Competition Laws and Their Effects' (2007) 74 Antitrust LJ 271

Provided by:

Fineman \& Pappas Law Libraries

-- Your use of this HeinOnline PDF indicates your acceptance of HeinOnline's Terms and Conditions of the license agreement available at https://heinonline.org/HOL/License

-- The search text of this PDF is generated from uncorrected OCR text.

-- To obtain permission to use this article beyond the scope of your license, please use: Copyright Information 


\title{
ANTITRUST AROUND THE WORLD: AN EMPIRICAL ANALYSIS OF THE SCOPE OF COMPETITION LAWS AND THEIR EFFECTS
}

\author{
KEITH N. HyLtON \\ FEI DENG*
}

\section{INTRODUCTION}

Since the early studies of Arnold Harberger, ${ }^{1}$ George Stigler, ${ }^{2}$ and Richard Posner, ${ }^{3}$ there has been a growing movement calling for the use of empirical evidence to judge the effectiveness of antitrust law in securing its goals. ${ }^{4}$ That there have been relatively few such studies is attrib-

\footnotetext{
* The authors are, respectively, Professor of Law, Boston University; and Consultant, NERA Economic Consulting. The authors thank participants at presentations at the 2006 ABA Antitrust Annual Meeting, the 2006 AALS Annual Meeting, the Conference on Empirical Legal Studies at Texas, and Georgetown Law School. In addition, Daniela Caruso, Francisco Marcos, Michael Meurer, Steve Salop, Markus Saurer, Daniel Sokol, David Walker, Josh Wright, and Rafael LaPorta provided helpful comments. The authors also thank Nicola Leiter and Sean Miller for helping develop the dataset. Haizhen Lin provided excellent research assistance. Finally, the authors thank the Joumal referees for many helpful suggestions.

${ }^{1}$ Arnold C. Harberger, Monopoly and Resource Allocation, 44 AM. ECON. REv. 77 (1954).

${ }^{2}$ George J. Stigler, The Economic Effects of the Antitrust Laws, 9 J.L. \& ECON. 225 (1966).

${ }^{3}$ Richard A. Posner, A Statistical Study of Antitrust Enforcement, 13 J.L. \& ECON. 365 (1970).

${ }^{4}$ For a single volume that contains many empirical studies of antitrust, see THE CAUSES and Consequences of ANtitrust: The Public-Choice Perspective (Fred S. McChesney \& William F. Shugart II eds., 1995). In 2003, the Joumal of Economic Perspectives published a debate on the effectiveness of antitrust law. See Jonathan B. Baker, The Case for Antitrust Enforcement, 17 J. ECON. PerSP., Fall 2003, at 27; Robert W. Crandall \& Clifford Winston, Does Antitrust Policy Improve Consumer Welfare? Assessing the Evidence, $17 \mathrm{~J}$. ECON. PERSP., Fall 2003, at 3. For additional commentary on the Journal of Economic Perspectives debate, see Gregory J. Werden, The Effect of Antitrust Policy on Consumer Welfare: What CRANDALL AND WINSTON OvERLOOK (AEI-Brookings Joint Center for Regulatory Studies ed., Apr. 2004), available at http://aei.brookings.org/admin/authorpdfs/page.php?id=933. The most recent empirical studies attempt to assess the impact of competition law using data from a broad sample of countries. See Bernard Hoekman \& Hiau Looi Kee, Imports, Entry and Competition Law as Market Disciplines (CEPR Discussion Paper No. 3777, Feb. 2003), available at http://ssrn.com/abstract=392682); Michael Krakowski, Competition Policy Works: The Effect of Competition Policy on the Intensity of Competition-An
} 
utable to the lack of useful statistical information on the law, enforcement policies, and penalties.

In this article, we present an effort to use information on competition laws around the world to assess their scope and effectiveness. The foundation of this study is a dataset that codes key features of the competition laws of 102 countries. $^{5}$ It first compares the scope of the laws overall and then assesses various subcomponents, such as the law governing dominance, collusive conduct, and mergers. The second question examined is whether a nation's competition law has any effect on the intensity of competition within its borders. ${ }^{6}$

Coding information on the law permits us to compare competition law regimes according to a fixed though somewhat arbitrary metric. Moreover, it allows us to summarize a rich array of information from more than 100 countries in compact form. Key to our approach is the construction of "scope indexes" to measure the breadth of the overall competition law and that of various subparts, such as the law on dominance or mergers. The indexes provide quantitative measures of the size of the overall "competition law net" in a country or the various smaller nets designed to cover specific subject matters. The quantitative measures could be treated as measures of "antitrust risk" within each country and region examined.

These comparative assessments would be quite difficult to do using a purely descriptive approach toward the law. Indeed, we are inclined to argue that the primary goal of this article is to encourage the gathering of statistics on the law of competition and its enforcement procedures and penalty provisions. As a theoretically and doctrinally top-heavy field, the time has long passed for antitrust law to be subjected to empirical analysis.

\footnotetext{
International Cross-Country Comparison (HWWA Discussion Paper No. 332, Sept. 2005), available at http://ssrn.com/abstract=854908; Stefan Voigt, The Economic Effects of Competition Policy-Cross-Country Evidence Using Four New Indicators (Sept. 2006), available at http://ssm.com/abstract=925794. For region-specific empirical studies, see Russell W. Pittman, Abuse-of-Dominance Provisions of Central and Eastern European Competition Laws: Have Fears of Over-Enforcement Been Borne Out? 27 WORLd COMPETITION 245 (2004); Maria Coppola Tineo \& Russell W. Pittman, Abuse of Dominance Enforcement Under Latin American Competition Laws (Mar. 2006), available athttp://ssrn.com/abstract= 888186.

${ }^{5}$ Keith N. Hylton, Sean Miller, \& Nicola Leiter, Antitrust Around the World Database, Boston University Law School (Aug. 2006) (on file with authors).

${ }^{6}$ We have examined the entire sample rather than a subset consisting of the richest countries, developing countries, or some other subdivision. Although it would be worthwhile to examine the effects of competition law in some special set of countries (e.g., developing countries), such a study is beyond the scope of this article.
} 
The first part of our study examines the variation in the scope of competition laws around the world. With 102 countries, we have presented much of our comparative analysis on the basis of regions (North America, South America, EU Europe, etc). In terms of overall scope, the strongest regions are predictably North America and EU Europe. If the scope of EU competition law is determined on the basis of national competition statutes, EU Europe follows closely behind the North America region. If, on the other hand, the scope of EU law is determined on the basis of EU Treaty law, EU Europe is by far the strongest region in the world. The weakest regions are South America and Central America. However, there are some findings that go against predictions based on intuition or common information. For example, Central America, while overall weak, is one of the stronger regimes in terms of collusive practices-the parts deemphasized there are mergers and monopoly abuse.

There is a long-held view that regulation responds to citizen preferences and willingness to pay, ${ }^{7}$ which implies that the scope of competition law will vary with national income. This assumption is largely confirmed in the regional comparisons of the Scope Index. Africa's competition laws, however, are considerably more extensive than one would expect on the basis of national income rankings, and South America's are weaker.

The second part of this article uses a measure of the overall scope of the country's competition law (Scope Index) to determine whether the size of a country's competition law net is associated with the intensity of competition in that nation's economy. We use two variables as proxies for the intensity of competition. One, a subjective measure, is the World Economic Forum's (WEF) survey measure of the perceived intensity of local competition. ${ }^{8}$ The WEF's survey measure runs from a low of 1 (perception that competition is limited) to 7 (competition is perceived as intense). The other variable, an objective proxy, is the Purchasing Power Parity (PPP) exchange rate. ${ }^{9}$

We find evidence, in ordinary least squares regressions, that the scope of a country's competition law is associated positively with the perceived intensity of local competition. Specifically, a one-point increase in the

7 See, e.g., Dennis C. Mueller, Public Choice II 320-27 (1989).

8 WORLd ECONOMic Forum, Global Competitiveness Report 2004 at 506; World ECONOMIC Forum, Global COMPETITIVENESS RePORT 2003 at 623 . The competition intensity measure is based on a survey of a large sample of business leaders and entrepreneurs. See http://www.weforum.org/en/initiatives/gcp/index.htm. The competition intensity survey measure is defined as follows: Intensity of Local Competition: Competition in the local market is $1=$ limited in most industries and price cutting is rare; $7=$ intense in most industries as market leadership changes over time.

${ }^{9}$ For a description of PPP, see infra text accompanying notes 51-52. 
Scope Index, our measure of the law's scope, is associated with a .02 increase in the WEF's competition intensity survey measure. As the WEF's competition intensity measure runs from 1 to 7 , and the Scope Index runs from 0 to 29 , this result suggests a limited competitionenhancing impact, at best, for the law. ${ }^{10}$

We also examine the effects of various components of competition law, such as the laws on dominance, restrictive trade practices, mergers, and penalties. Our regressions suggest that enhancing enforcement, by permitting private actions or increasing the range of remedies available to enforcement authorities, has the largest impact on perceived competition intensity. There is also some evidence that increasing the scope of the law governing concerted activity enhances the perceived intensity of competition. On the other hand, we find no evidence that increasing the scope of merger or dominance law enhances perceived competition intensity-indeed, there is weak evidence that increasing the scope of dominance law reduces the intensity of competition.

Of course, given the subjective nature of the proxy for competition intensity, ${ }^{11}$ as well as causation issues, this evidence should be taken as tentative or preliminary at best. In addition, we find no evidence that increasing the scope of a country's competition law has an impact on our objective proxy for competition intensity, PPP. ${ }^{12}$ Of course, this result could be interpreted as evidence that PPPs are simply poor proxies for the effect of competition intensity on prices.

There are serious causation or endogeneity issues that suggest that the estimates of the impact of the Scope Index, based on ordinary least squares regressions, are biased. The least squares estimates in the regressions that use the subjective proxy are based upon an assumption that the scope of the law influences the perceived intensity of competition and is not itself simultaneously influenced by the perceived intensity of competition. This assumption is questionable in the context of competition law.

\footnotetext{
${ }^{10}$ For example, suppose a country's WEF competition intensity score is 4, and suppose the Scope Index for that country is 15 . If the country moved 10 places up on the Scope Index (from 15 to 25 ), its competition intensity score would increase, all else held the same, from 4 to 4.2. For further discussion, see infra text accompanying notes 50-51.

"In defense of the subjective measure, we argue that perception is probably accurate in most cases and may be just as important as the "real" level of competition intensity. Perception, rather than reality, will drive the strategies adopted by firms.

${ }^{12}$ For another study that attempts to assess the impact of competition law on an objective measure and fails to find a statistically significant impact, see Hoekman \& Kee, supra note 4 . Voigt also uses objective measures and finds mixed results for his competition law variables. See Voight, supra note 4.
} 
In view of these issues, we ran instrumental variables regressions, which avoid the bias due to endogeneity, in order to see if the statistically significant impact of the law's scope could be replicated within that framework. The instrumental variable regressions, however, fail to show a statistically significant impact for the law's scope.

Two statements can be offered to sum up the results of our study. First, the most obvious overall assessment of the results on effects is that they are preliminary and the ultimate conclusions will depend on more data. Given this limitation, the primary payoff of this study is its comparative analysis and its illustration of the potential approaches and pitfalls of empirical analysis of competition law's effects. Second, the analysis of effects offers mild preliminary support for the claim that competition law has a positive, though quite limited, effect on the intensity of competition within a nation. Moreover, much of that positive impact appears to be due to the strength of enforcement in particular areas rather than the scope of the substantive law. The support found here for the effectiveness of competition law is weak, it should be stressed, and we are not confident that it will withstand further empirical scrutiny. But that is to what it must be subjected.

Viewing the rather mixed evidence in our study in a light most favorable to competition law, we see simple policy implications. The results suggest that competition law can be effective in enhancing the intensity of competition, largely through reducing collusive practices, provided that the enforcement threat is significant. The results do not suggest that merger or dominance law enhance competition intensity.

The value of our approach should be assessed in light of the existing empirical antitrust literature, which can be divided into three categories. The first category consists of the early studies, which focused on evidence from the United States. ${ }^{13}$ The second category consists of studies using international data on competition regimes from a large sample of countries. Some of these studies use only a single dummy variable to code for the existence of a competition law. ${ }^{14}$ Another set of studies in the second

\footnotetext{
${ }^{19}$ Harberger, supra note 1; Stigler, supra note 2; Posner, supra note 3 . Among these articles, George Stigler's article is the only one to make international comparisons, though it is limited to the United States and England. In addition to these early studies, we would include in this category other empirical assessments that focus on evidence from the United States alone. See, e.g., Crandall \& Winston, supra note 4, at 17-20 (examining industry price-cost margins and the effects of merger enforcement).

14 See Mikyung Yun et al., Competition, Competitiveness and Development: Lessons from Developing Countries, UNITEd NATIONS CONFERENCE ON DEVELOPMENT AND TRADE 259-330 (2005), available at http://www.unctad.org/en/docs/ditcclp20041_en.pdf; Hoekman \& Kee, supra note 4.
} 
category use survey-based measures of competition law and enforcement, which provide considerably more information on the law's scope than is possible with the dummy variable approach. ${ }^{15}$ Our approach represents a third category of empirical antitrust study, which differs from previous efforts in the other two categories by attempting to incorporate all of the competition regimes existing for the time period of the study (2001 to 2004) and using an objective measure of the law's scope rather than a survey-based measure. ${ }^{16}$ Our hope is that the broader sample will provide additional useful information and that the objective approach will avoid biases that might creep into survey evidence. ${ }^{17}$

\section{CODING COMPETITION LAW}

The foundation of this study is an attempt to code the competition laws of 102 countries. ${ }^{18}$ In order to do this, we developed a template, based upon the approach taken by Michael Nicholson. ${ }^{19}$ An example of the template appears in Appendix Table A1, which presents our attempt to code the competition laws of New Zealand.

In order to construct the template, we listed the types of conduct generally prohibited under competition laws, the types of penalties that might be assessed under the laws, and the procedures for enforcing those laws. Following Nicholson's method, ${ }^{20}$ we divided the law into several key categories: Territorial Scope, Remedies, Private Enforcement, Merger Notification, Merger Assessment, Dominance, and Restrictive Trade Practices. Our classification system differs from that of Nicholson only in the Merger Assessment category, where we included information on "public interest" tests used in some merger statutes (see Appendix Table A1). We searched each country's competition statute to determine whether the prohibition or procedure is included within the country's law, which generates the second and third columns of Table Al.

In some cases, the country's competition statute revealed too little information about prohibited conduct to be useful as the sole source of

${ }^{15}$ Krakowski, supra note 4; Voigt, supra note 4.

${ }^{16}$ Our study builds on the approach in Michael W. Nicholson, Quantifying Antitrust Regimes (FTC Bureau of Economics Working Paper No. 267, Feb. 2004), available at http://ssrn.com/abstract=531124. Nicholson, however, uses a much smaller sample than we use.

${ }^{17}$ For discussion of one possible bias in survey measures, see infra text accompanying notes $57-58$.

${ }^{18}$ See Appendix, Table A4.

${ }^{19}$ Nicholson, supra note 16 .

${ }^{20} \mathrm{Id}$. 
information. The most famous example is the United States, which has the Sherman Act at the foundation of its competition laws. The core of the Sherman Act consists of two short provisions: Section 1, governing cartels, and Section 2, governing monopolies (or dominant firms). In these cases, we examined common law and other reports to fill in the template. Most countries, however, have their competition laws codified in a statute or series of statutes.

As competition laws are changing all the time, we were forced to restrict our time period. The information we have coded covers January 2001 to December 2004. Changes in competition law that occurred after December 2004 are not reflected in our study. In some cases, a country's law changed between 2001 and 2004. When this occurred, we filled out two (or more) templates to reflect the different regimes within a particular country during the time period of our sample. Ideally, a study such as this one would attempt to code for the status of each country's competition law for each time period of its existence. This approach would generate a sample running from 1889, the date Canada's competition law was enacted, to the present. Given our limited time period, this study should be viewed as a preliminary or provisional attempt to lay the groundwork for a much larger project.

This approach is, admittedly, a crude attempt to code the law. The template does not permit us to code for detailed differences in the competition laws among countries. For example, predatory pricing is prohibited, as a matter of formal law, in both the United States and the European Union. The detailed common law, however, reflects important differences between the two regimes. The Brooke Group test has erected an extremely difficult evidentiary burden for predation plaintiffs in the United States, requiring them to show that price is below some proxy for marginal cost and the defendant had a strong likelihood of recouping its predatory investments. ${ }^{21}$ European predation law, however, does not include a recoupment test and sets up a presumption of unlawful predation if price is below some proxy for marginal cost. ${ }^{22}$ The practical result is that although predation is prohibited by the competition laws of both Europe and the United States, predation plaintiffs expect to lose in the United States while they are not so pessimistic in Europe.

${ }^{21}$ Brooke Group, Ltd. v. Brown \& Williamson Tobacco Corp., 509 U.S. 209, 240-42 (1993); Matsushita Elec. Indus. Co. v. Zenith Radio Corp., 475 U.S. 574, 595-98 (1986).

${ }^{22}$ See, e.g., Case T-83/91 Tetra Pak Int'l SA v. Commission, 1994 E.C.R. II-755, 4 C.M.L.R. 726 (1997), aff'd, C-333/94, 1996 E.C.R. I-5951, 4 C.M.L.R. 662 (1997); Case C-62/86, AKZO Chemie BV v. Commission, 1991 E.C.R. I-3359; see also John Vickers, Abuse of Market Power, 115 ECON. J. F244, F248 (June 2005). 
Another shortcoming of the template in Table Al is that it includes categories that may overlap with other categories. For example, the list of prohibited types of conduct for dominant firms includes "abusive acts" and "obstacles to entry." In most competition law regimes, the creation of an obstacle to entry by a dominant firm is simply a type of abusive act. Consequently, we treated the abusive act line of the template as a catchall that includes within it some of the more specific types of conduct included in the dominance portion of the template.

Yet another potential source of error is that the statutes are sometimes poorly written or written in such general terms that it is difficult to infer precisely what is prohibited. For example, a statute that prohibits "abusive acts" by dominant firms may or may not prohibit predatory pricing. As we noted earlier, we attempted to patch these cases by referring to case law or reports on enforcement. This approach, however, is bound to result in some inconsistencies.

We attempted to minimize distortions created by the foregoing list of potential flaws by creating a set of definitions and attempting, as much as possible, to remain consistent with those definitions in coding the law. ${ }^{23}$ In the end, we are unable to say whether our categories and their associated definitions are optimal. Perhaps an optimal coding system would not assume, as we do here, that the category "abusive acts" may contain other specified acts, such as creating "obstacles to entry," as special cases. Some inconsistencies probably have resulted from our efforts to use a set of fixed definitions to code the law, but this limitation is unavoidable in any such effort.

For the most part, the codes consist of a binary variable of either "0" or "1," where "0" means that we could not find any provision in the law governing the specified conduct, penalty, or enforcement procedure. The key exception is found in the codes for merger notification regime. Some competition law regimes require notification, while others simply permit or encourage notification ${ }^{24}$-this distinction is between mandatory and voluntary merger notification. In addition, some competition law regimes require notification before the merger takes effect, and others permit notification after the merger takes effect. ${ }^{25}$ Accordingly, there are four types of merger notification regime: mandatory premerger, voluntary premerger, mandatory postmerger, and voluntary postmerger. We chose a set of numbers that would rank the different merger notification

\footnotetext{
${ }^{23}$ See Appendix, Index Definitions.

${ }^{24}$ For examples, see id.

${ }^{25}$ For examples, see $i d$.
} 
regimes according to their restrictiveness. In terms of restrictiveness, we assumed the regimes should be ranked in the following order (from most to least restrictive): mandatory premerger, mandatory postmerger, voluntary premerger, voluntary postmerger. The numerical codes used for the merger notification portion guarantee this ranking of regimes. ${ }^{26}$

Instead of coding the law from national competition statutes, there is the alternative of coding law that takes into account the effects of regional treaties, the most important of which is the European Union Treaty. Because of the Treaty, member states of the European Union have a dual competition law regime. Competition disputes that are relatively large, in the sense that they affect trade among EU states, are resolved under EU law. ${ }^{27}$ Competition disputes that are relatively small are resolved under the national competition statute. This system means that in a practical sense there are two sets of competition law in every EU member state, one for big firms and one for small firms.

Even for large firms that conduct trade among EU member states, EU law is not the sole source of competition law that concerns them. Although EU law has a largely preemptive effect in the area of mergers, dominant firms, and restrictive trade practices; the European Union will allow the member state to apply its own law with respect to an abuse of dominance if that law is more stringent than that of the European Union. ${ }^{28}$ In addition, the key area in which the EU law is not preemptive is that of private rights. Private enforcement is largely determined by the national competition statute. Specifically, whether an individual can sue for an antitrust violation and collect damages is a matter of the individual EU member state's competition statute. ${ }^{29}$ The appendix presents two completed templates for Belgium. The first one (Appendix Table A2) is based entirely on Belgium's competition statute. The second merges Belgium's law with that of the European Union.

${ }^{26}$ For the individual country templates, we used the following values: mandatory $=3$, voluntary $=1$, premerger $=2$, postmerger $=1$. With these values, mandatory-premerger $=$ 5 , mandatory-postmerger $=4$, voluntary-premerger $=3$, and voluntary-postmerger $=2$. For computing the index measuring the scope of the law, we reduced each of these scores by one, so that the ranking of merger notification regimes increases by one-digit increments from 0 (no requirements) to 4 (mandatory-premerger).

${ }^{27}$ See, e.g., Wouter P.J. Wils, The Modernization of the Enforcement of Articles 81 and 82 EC: A Legal and Economic Analysis of the Commission's Proposal for a New Council Regulation Replacing Regulation No. 17, 24 FORDHAM INT'L L.J. 1655, 1656 (2001).

${ }^{28}$ See, e.g., William M. Hannay, Transnational Competition Law Aspects of Mergers and Acquisitions, 20 Nw. J. INT'L L. \& Bus. 287, 291 (2000).

${ }^{29}$ Clifford A. Jones, Private Enforcement of Antrtrust LaW in the EU, UK and USA 46 (1999). 


\section{VARIATION IN COMPETITION LAWS}

In this section, we present a statistical and visual summary of the regional differences and variation in competition law regimes. The reason for examining regional differences is that they communicate a rough snapshot of the variation across regimes without burdening the reader with details on the competition laws of more than 100 countries. In addition, comparison of regional differences could be of value to a firm that operates regionally and has to assess the degree of "antitrust risk" in its area of operation.

We are aware of some of the drawbacks of the regional approach to comparisons. One appears in the case of Europe. We have divided the Europe sample into EU Europe and non-EU Europe. EU Europe consists, in this sample, of the fifteen countries that were members during most of the time period of this sample, 2001-2004 (Austria, Belgium, Denmark, Finland, France, Germany, Greece, Ireland, Italy, Luxembourg, Netherlands, Portugal, Spain, Sweden, United Kingdom), plus the ten additional countries that were awaiting admission into the European Union for most of this period and became members in May 2004 (Cyprus, Czech Republic, Estonia, Hungary, Latvia, Lithuania, Malta, Poland, Slovakia, and Slovenia). We decided to include the ten countries awaiting admission in the EU sample because these countries had strong incentives to bring their law into line with $\mathrm{EU}$ law during the waiting period.

Another problem with the EU Europe category, noted above, is that the competition law of each of the EU countries falls under a general framework provided by the EU Treaty. In general, EU law applies to matters that affect trade among the member states-in other words, undertakings by big firms trading across state borders. This scope means that the national laws are to some extent preempted, especially in the area of "restrictive trade practices," which includes collusive conduct.

Obviously, a study of the laws declared in the national statutes of European countries fails to reflect the preemptive effect of EU law. On the other hand, the case for using information from the statutes of individual EU nations is that the individual statutes probably reflect domestic priorities. Although EU law applies to the big transnational matters in every member state, the zeal with which a particular state's competition authority enforces EU competition law may be better reflected by the scope of that state's competition statute. A country with a national statute that prohibits relatively few potentially anticompetitive acts has revealed a preference for a laissez-faire competition regime. That preference is likely to be reflected in that country's attentiveness toward enforcing EU competition law. 
Given the choice in the case of the European Union between coding information from national competition statutes and EU competition law, we have chosen to present information from both. We will present comparative results based entirely on national competition statutes, as well as results that incorporate $\mathrm{EU}$ competition law.

This approach is not as simple as merely coding for a common set of laws for all twenty-five EU members. For member states, EU law preempts some parts of the law, gives states options with respect to some parts, and opts for state law in other contexts. Specifically, EU law preempts the substantive law regarding restrictive trade practices. For restrictive trade practice disputes that come within the jurisdiction of the European Commission, individual member states are not free to apply rules that deviate from EU law. ${ }^{30}$ With respect to dominance, member states are permitted to apply the law of their national statutes if that law is more restrictive than that of the European Union. ${ }^{31}$ Of course, as a practical matter, the EU's law is the most restrictive. Finally, with respect to private rights of action, the law of the individual member state controls. ${ }^{32}$

\section{A. Measuring the Scope of Competition law}

\section{Scope Index}

The first charts we present Scope Index scores. These scores are found by summing the total points within each country template and then subtracting the defense scores. For example, the Scope Index score for New Zealand is found by summing the numerical values in the template shown in Table 1 and then subtracting scores associated with defenses (and one point to reduce the merger subtotal). In the case of New Zealand, there are three defenses (merger public interest defense, efficiency defense for dominant firms, efficiency defense for restrictive trade practices). The sum of the points is 19 (after reducing the merger subtotal), and, after subtracting 3, the Scope Index for New Zealand is 16. For each EU member state, an alternative Scope Index was computed based on EU law. ${ }^{33}$

${ }^{30}$ Council Regulation 1/2003 of December 16, 2002, Regarding the Implementation of Competition Rules Laid Down in Articles 81 and 82 of the EC Treaty, art. 3(2), 2003 O.J. (L 1) $1,8$.

${ }^{31}$ Id.

${ }^{32}$ See Wils, supra note 27.

33 See Appendix Table A2 for an example of templates for Belgium based on national law and on EU law. 
The point of the Scope Index is to measure the size of the competition law net in every country. As the score increases, so does the size of the net. Alternatively, one can think of the Scope Index for a particular country as a measure of the number of ways in which a firm could run afoul of the competition laws in that country. The Scope Index score, however, does not indicate the degree to which a country invests resources into enforcing its competition laws. Continuing with the net metaphor, the Scope Index tells us the size of the competition law net without saying anything about the likelihood that a government will attempt to swing the net at any firm.

Figures 1 and 2 present histograms of the number of countries for each Scope Index score. The first histogram shows the Scope Index scores after modifying each EU member state's law to reflect that of the EU. The second histogram shows the scores based entirely on national competition statutes. The histograms are shaded for region so that the distribution of scores within each region can be observed in the chart. ${ }^{34}$

Why look at both histograms? Clearly, a large firm operating within the European Union should worry about EU law. Why, then, should we consider the Scope Index based on national statutes? Several reasons can be offered. First, the law based on national statutes may provide a more accurate picture of the "real law" in every nation because the national statutes presumably reflect local legislative preferences. At the least, the national statutes provide a measure of the minimum that should be expected of the national competition regimes. Second, an enterprise or concerted practice may be of a sort that, if located in Europe, would operate entirely within the borders of an EU member state. A price-fixing conspiracy, for example, might target the consumers of a specific country.

Figure 1 suggests immediately that for large firms-firms that would operate across borders if located within the European Union-antitrust risk as measured by the law on the books is quite a bit higher in the European Union than in any other region of the world. The countries with the highest score (28) are all in the Eropean Union as of 2004: Austria, Cyprus, Estonia, France, Ireland, Spain, and the United Kingdom. By comparison, the score for the United States is 25. The country with the lowest score (2) is Paraguay.

Figure 1 has a roughly bimodal shape, suggesting that, at least for large enterprises, antitrust risk can be described in terms of a division

${ }^{34}$ See Appendix Table A6 for a list of the countries within each region. 
between the European Union and the rest of the world. The modal Scope Index for the EU region is 27, while that for the rest of the world is 20. Most of the countries at the rest-of-the-world modal score are from Asia and non-EU Europe. South American competition law regimes appear to be the weakest, measured in terms of the scope of the laws. Competition law regimes in Africa and in Central America are distributed evenly over the non-EU scores.

Figure 2 presents Scope Index scores based entirely on national statutes. Even when EU law is not taken into account, the most extensive national competition laws are generally found in EU Europe. Although, surprisingly, none of the EU Europe countries are among those with the highest Scope Indexes (based on national codes), most of the EU countries have scores in the upper half of the distribution, ranging from 18 to 24. The countries with the highest scores (25) are Australia (Oceania), Barbados (Caribbean), Belarus (non-EU Europe), Malawi (Africa), and the United States (North America).

Both histograms show that African countries have more extensive laws than one might have guessed. One of the highest scores in Figure 2 belongs to an African country, Malawi, and the African countries are fairly evenly distributed over the range. Our intuition initially was that the group of relatively poor developing countries, of which Africa has a disproportionate share, would be the last to devote scarce resources to competition law. ${ }^{35}$ This intuition, however, appears to be wrong.

If one were operating a company with a regional business base, the regional differences in competition law might be an important factor to consider. Exposure to antitrust risk is greatest in EU Europe and lowest in South America, Central America, and Africa. Of course, one might have predicted right away that these differences would be observed. Wealthier countries have more money to spend on their regulatory preferences than do poor countries. However, the chart allows one to quantify the magnitude of the differences, which we will explore in more detail shortly. Moreover, it reveals some anomalies, the most prominent of which is that Africa is stronger in terms of the scope of its competition laws than South America, which is the opposite of what one would expect if predicting on the basis of wealth.

${ }^{35}$ One possibility is that the relatively poor countries have competition laws "on the books" but devote few resources to their enforcement. But the law-making process is itself costly, given that scarce legislative capacity devoted to drafting competition laws could instead be invested in other laws that might have a more immediate effect on social welfare (e.g., increasing the supply of mosquito nets). Even if the competition laws are rarely enforced in relatively poor countries, they may have a substantial effect on incentives if the penalties associated with violations are high. 
The Scope Index presented in Figures and 1 and 2 measures the number of ways in which a firm could get into trouble under a nation's competition law, but says nothing about the number of defenses that are available to a firm. In other words, the Scope Index measures the size of the net without saying anything about the number of holes in it. In order to get a measure of the size of the net that also takes into account exceptions, we generated an alternative scope measure based on the scope score net of defenses. The alternative measure was calculated by taking the Scope Index for each country and subtracting from the total score for the defenses permitted under the law. The total score for defenses was computed by adding up scores for efficiency defenses permitted in the law and for the public interest defense in merger statutes. The bimodal shape that appears in Figure 1 and the roughly bell-shaped curve of Figure 2 were both replicated by the alternative scope measure taking defenses into account. However, subtracting defenses from the Scope Index generated a tighter distribution, with the highest scores moving toward the median. This result occurred because the regimes with the most extensive antitrust prohibitions also have the most extensive defenses.

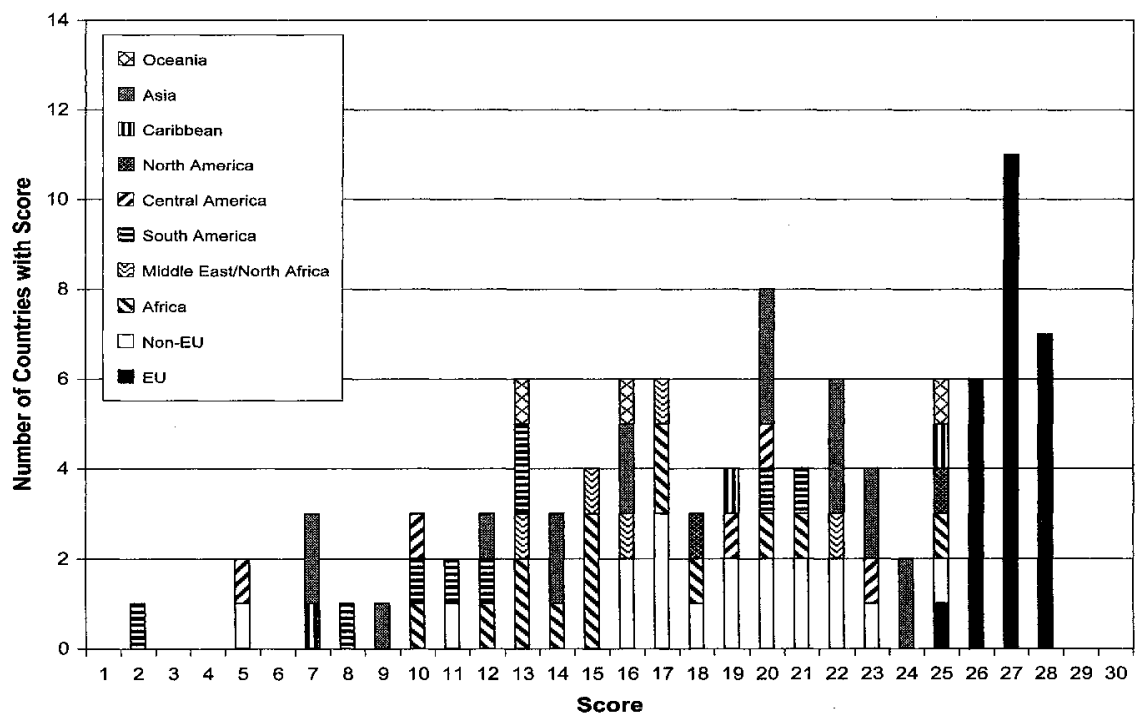

Figure 1. Histogram of Scope Index (with EU law, and without reductions for defenses) 


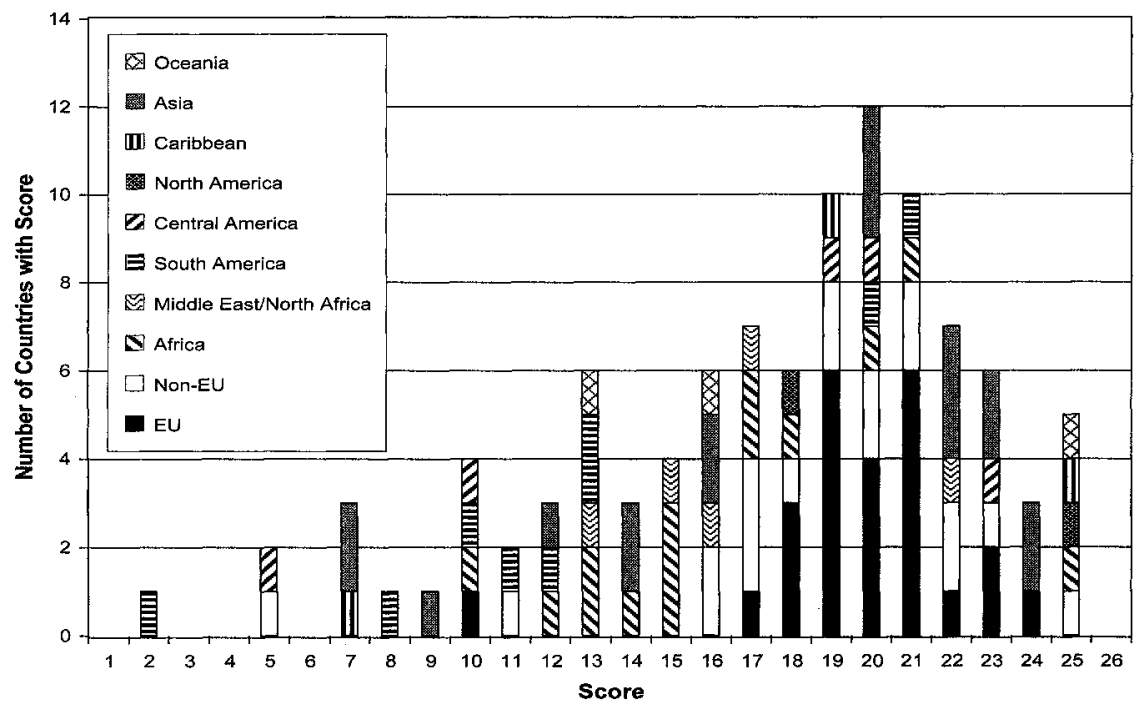

Figure 2. Histogram of Scope Index (national codes, and without reductions for defenses)

\section{B. Regional Comparisons by Subject Matter}

In this section, we compare regions according to the overall Scope Index and various sub-indexes measuring the scope of the law on certain subject matters, such as dominance (or, equivalently, monopolization). These comparisons provide a more detailed picture of the regional variation in the law and allow us to quantify regional differences in the law.

\section{Scope Index}

The first comparison is of regional differences in the Scope Index. As both Figures 3 and 4 indicate, consistent with the histograms shown earlier, the strongest regimes are those of EU Europe and North America, followed by non-EU Europe. When using EU law (Figure 3), rather than the national competition statutes, the EU region is by far the strongest. When using national statutes (Figure 4) to determine the scope of regional competition laws, North America leads the European Union. The weakest regimes are Central America and South America. The Middle East/North Africa, Caribbean, and Asian countries make up the middle ground. 
Because the Scope Index scores can be considered as measures of the size of the competition law nets in these various regions, we can make rough quantitative assessments of the differences in legal regimes. Under this approach, the competition law net in Africa, as measured by laws on the books, is 31 percent larger than that in South America. The North American competition law net is 75 percent larger than that of South America. The competition law net for EU Europe, based on EU law rather than the national statutes, is by far the largest, roughly 25 percent larger than that of North America and more than double that of South America.

One gets a sense from Figures 3 and 4 of the great disparity between EU competition law and most other regimes. If we treat the Scope Index as a measure of weight and we take the mean Scope Index as the rough balancing point for the various regimes, then Figures 3 and 4 show a dramatic change in balancing points when we shift from EU law to that of the national statutes. EU law and that of North America roughly balance the weight of the regimes from the rest of the world (Figure 3). When using national competition law statutes, the disparity in weights is not so great: The top four regions roughly balance the weight of the bottom five (Figure 4).

To translate this quantitative assessment of the law's scope into a statement about the risk of being penalized under a country's competition law requires the additional assumption that each country is equally likely to enforce the laws on its books. In other words, if the Scope Index is a measure of a country's competition law net, then it is a reasonable measure of antitrust risk only if enforcement authorities are equally likely to swing the net in each country. Obviously, this assumption is incorrect. But the thought exercise is still useful as a measure of antitrust risk on the assumption of equal enforcement efficiency across regimes. In addition, it suggests that an accurate measure of antitrust risk could be determined by decomposing risk into a legal component, based upon the scope of a country's laws, and an enforcement component, based on the zeal with which local enforcers pursue violators.

One obvious question to consider is whether the Scope Index increases with national income, reflecting the greater ability of richer countries to pay for the regulatory preferences. Table 1 shows the "average country GDP per capita" in 2005 (in U.S. dollars) in the regions used for this study, where this average is computed by averaging the GDPs of the countries within a regional category. For example, the $\$ 37,900$ figure for North America represents the average of the GDP per capita for Canada and the United States. As all of the countries used to complete the table have competition laws, the GDP per capita figures are in some 
cases higher than what would appear if we took the average of the per capita GDPs for all of the countries in each region. Comparing Table 1 to Figure 4, one observes that, except for cases of Africa and South America, there is a roughly monotonic relationship between regional average country GDP and the scope of competition law. Africa stands out as having a much broader set of laws than one would predict on the basis of regional income tables, while South America has weaker laws.

Scope Index

(Averages by Region)

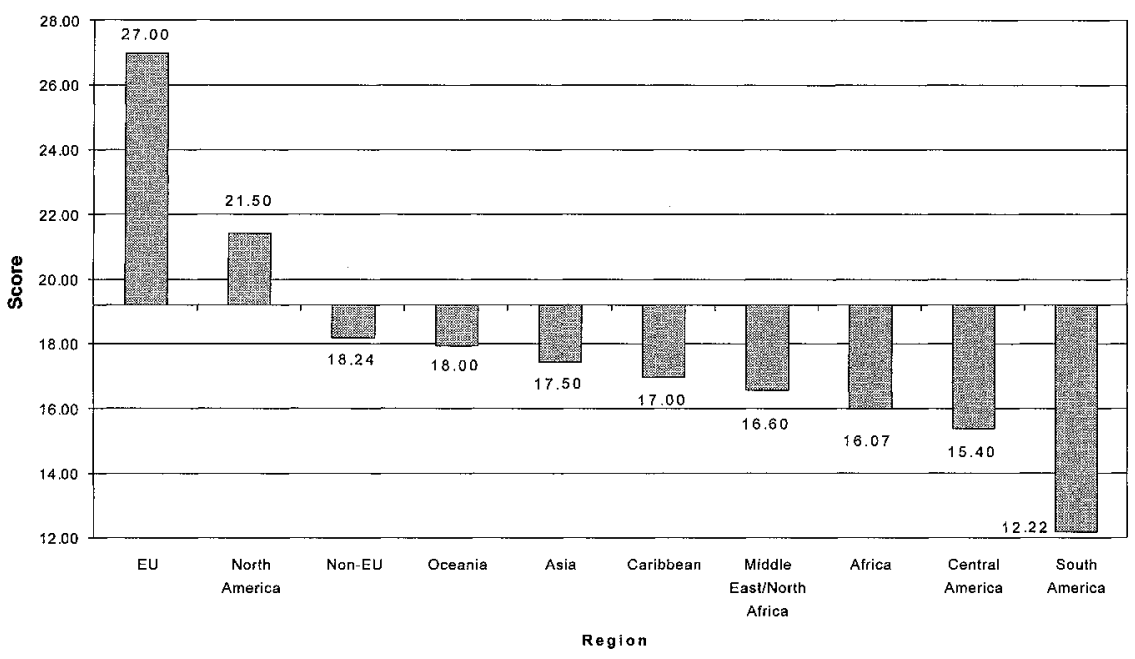

Figure 3. Scope Index by Region (EU law) 
Scope Index

(Averages by Region)

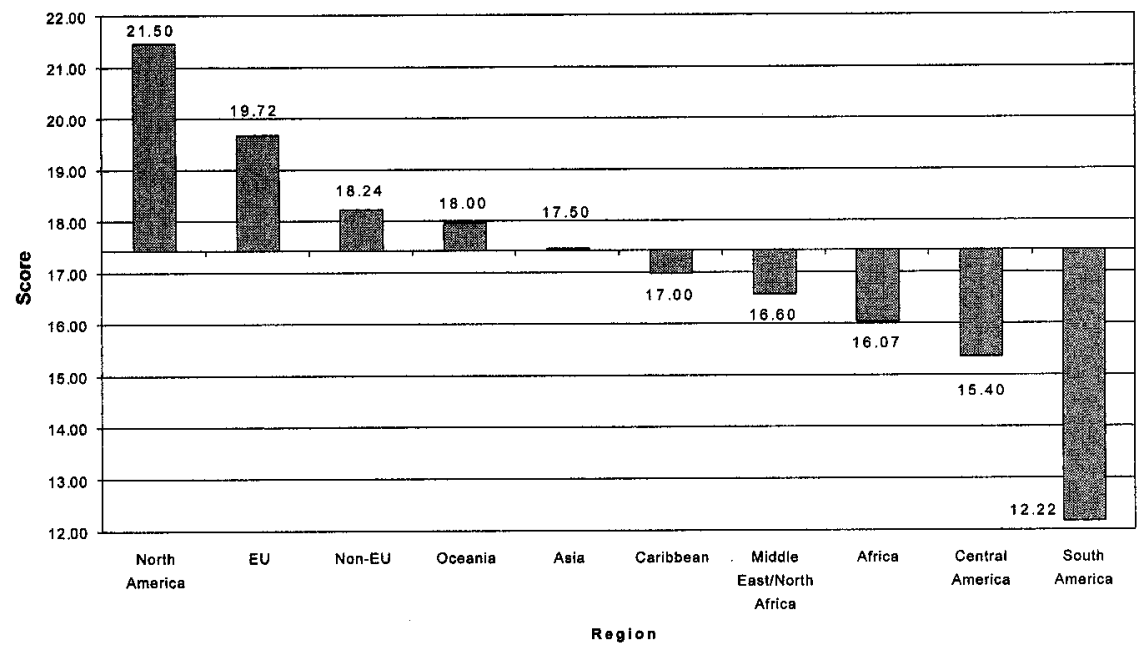

Figure 4. Scope Index by Region (national laws)

Table 1

Average Country GDP by Region, 2005 (among countries with a competition statute)

\begin{tabular}{lc}
\hline Country & $G D P$ \\
\hline North America & $\$ 37,900$ \\
EU & $\$ 25,804$ \\
Oceania & $\$ 19,900$ \\
Non-EU & $\$ 12,694$ \\
Middle East & $\$ 9,800$ \\
Caribbean & $\$ 9,466$ \\
South America & $\$ 7,788$ \\
Asia & $\$ 7,627$ \\
Central America & $\$ 7,540$ \\
Africa & $\$ 3,385$ \\
\hline
\end{tabular}




\section{Dominance Scores}

We turn our attention now to dominance law-or, in the language of American antitrust specialists, monopolization law. The Dominance Score is an attempt to measure the number of types of conduct specified in a country's competition law as unlawful abuse of a dominant position. For those familiar with American law, the dominance measure is an attempt to measure the scope of laws equivalent to Section 2 of the Sherman Act. One can think of the Dominance Score as the size of the net specifically designed to capture dominant firms that engage in anticompetitive conduct. $^{36}$

Figures 5 and 6 present the Dominance Scores. Again, the European Union and North America are the leading regions. The European Union leads if EU law is used rather than the national competition statutes (Figure 5), and North America leads if national competition statutes are used to assess the scope of dominance law (Figure 6). Of course, the lead enjoyed by the EU law is quite substantial: The dominance score for the European Union, based on EU law, is 33 percent larger than that for North America. When national competition statutes are used to assess the scope of dominance law, North America is only slightly ahead of the European Union.

The weakest regimes in terms of dominance law are Africa, Central America, and South America. South America and Central America remain the two weakest regimes, as they appeared in the comparison of Scope Indexes. However, whereas South America was the weakest region in terms of overall scope, Central America is the weakest in terms of dominance law.

The comparison based on national statutes indicates that most countries are either considerably above or considerably below the average (Figure 6), which is represented by the Middle East/North Africa (Algeria, Israel, Morocco, Jordan, Tunisia). Africa, consistent with our earlier description of the Scope Index, is among the weak regimes but is stronger than Central America and South America. This result is a bit surprising because one would think that attempting to control monopolies would be a low priority in relatively underdeveloped countries; and Africa, especially sub-Saharan, is unambiguously less developed than either the Central America or South America regions.

${ }^{36}$ The Dominance Scores were computed by summing all of the points in each country's template for the various types of conduct that are prohibited under the dominance section. For example, in the case of New Zealand (Table A1), the Dominance score is 4. 
Dominance Score

(Averages by Region)

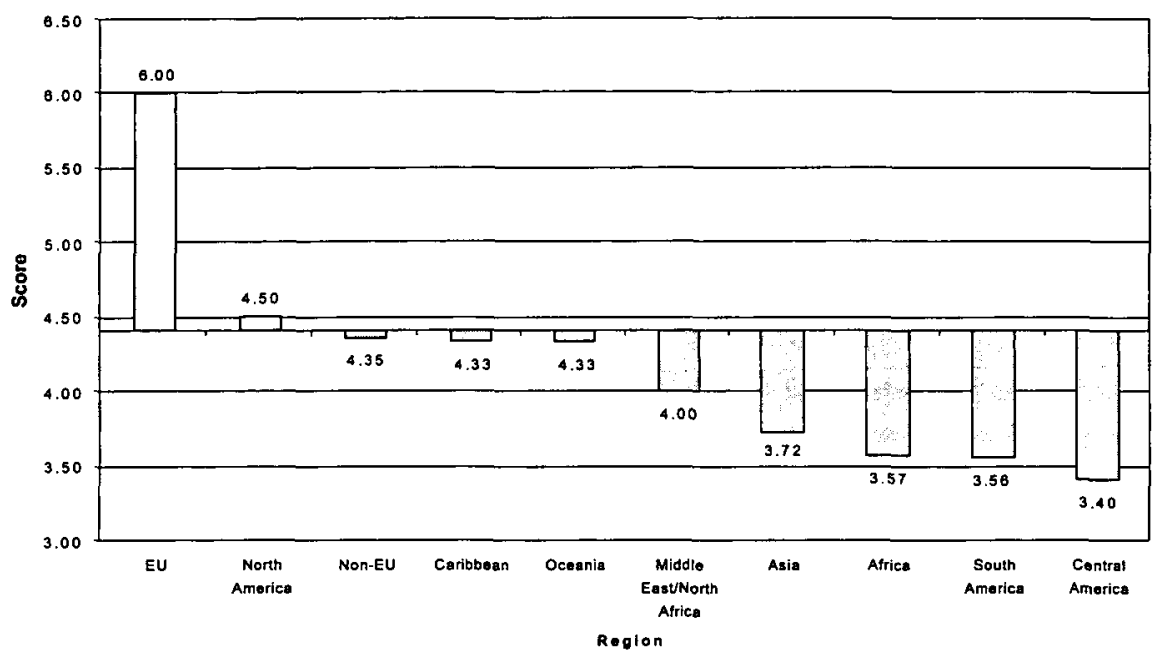

Figure 5. Dominance Score (EU law)

Dominance Score

(Averages by Region)

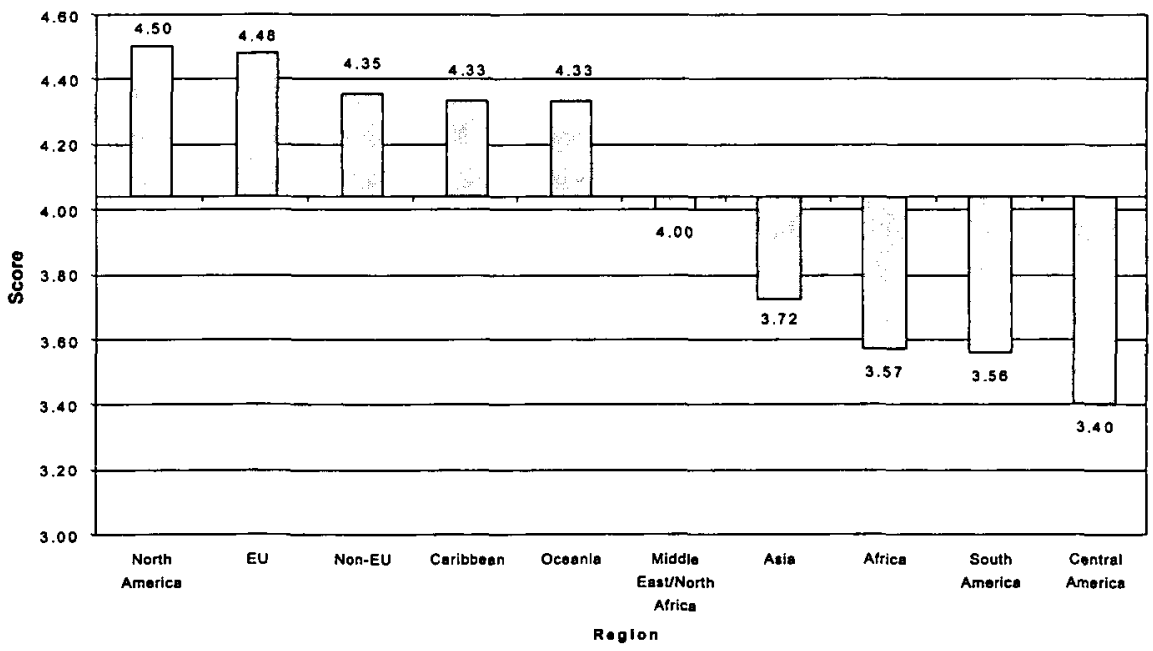

Figure 6. Dominance Score (national laws) 
Restrictlve Trade Practice Score

(Averages by Region)

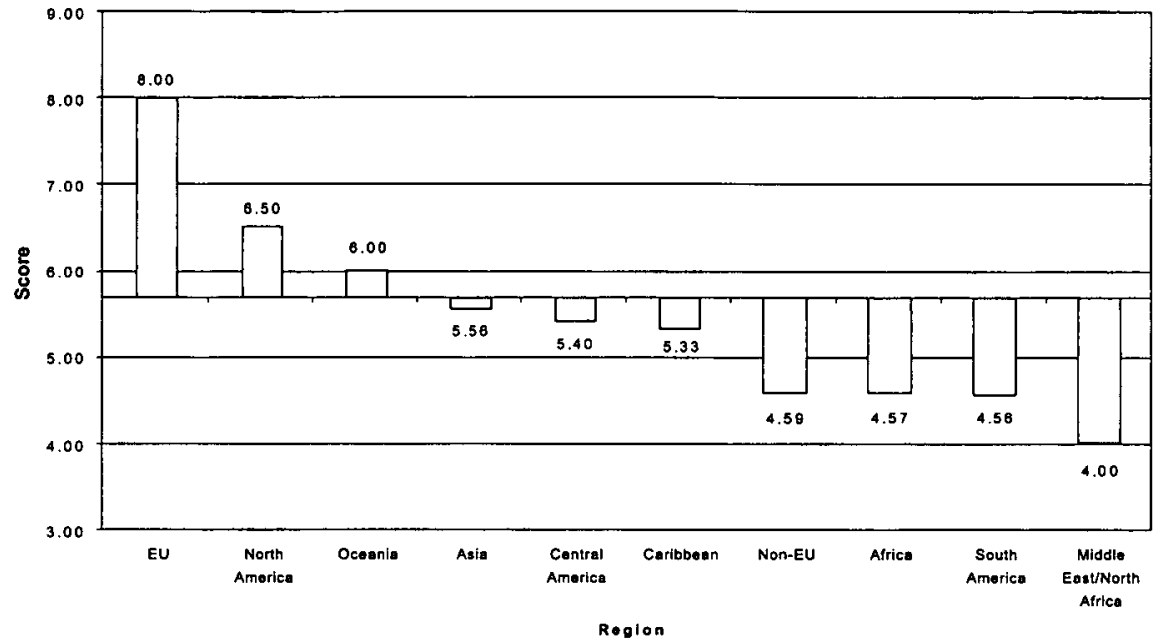

Figure 7. Restrictive Trade Practices (EU law)

Restrictive Trade Practice Score

(Averages by Region)

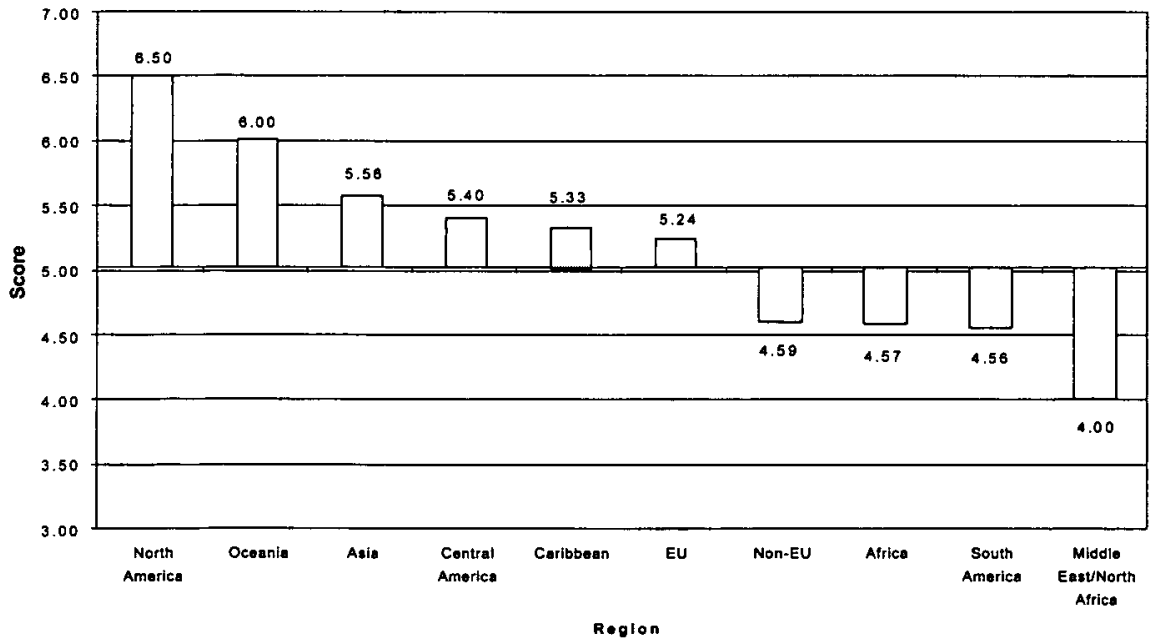

Figure 8. Restrictive Trade Practices Score (national laws) 


\section{Restrictive Trade Practices}

The term Restrictive Trade Practices refers to collusive conduct and agreements that restrain trade-conduct that would fall under Section 1 of the Sherman Act in the United States. ${ }^{37}$ Figures 9 and 10 examine the scope of laws governing restrictive trade practices by region. The Restricted Trade Practices score measures the size of the net designed specifically to catch firms that enter into agreements that restrain trade.

The first observation suggested by Figures 7 and 8 concerns the EU region. When using EU law as the source of European competition law, the European Union comes out in the lead on restrictive trade practices law (Figure 7). When using national laws as the source of European competition law, the EU region lands in the middle of competition law regimes (Figure 8 ). This illustration shows the dual competition law regime that exists in the European Union. As the national statutes are weaker with respect to restrictive trade practices, the rate of collusive activity among small firms that fall under the jurisdiction of national competition laws should be substantially larger than the rate of collusive activity among big firms in the European Union. Moreover, it implies that a group of big firms contemplating collusive conduct in the European Union would be well advised to carry out their plan through intermediaries that operate within a single member state, thus opting for a more lenient legal regime.

Both Figures 7 and 8 show that outside of the EU region, the top regimes are North America, followed by Oceania, whose position is largely based on the cartel laws of Australia and New Zealand. Asia is third, reflecting the extensive prohibitions in South Korea, India, and Taiwan. Central America is fourth, which is surprising in view of its generally weak competition laws. The explanation for the unusually strong showing for Central America is that of the five countries we put in this category (Mexico, Panama, Cost Rica, Guatemala, El Salvador), two of them (Mexico and Panama) have the highest scores possible on restrictive trade practices. In addition, although Costa Rica's laws governing anticompetitive agreements are far from the strictest, they are stricter than average. Thus, although Central America is a weak region overall in terms of competition law, it is relatively strong on cartel regulation. ${ }^{38}$

${ }^{37}$ The list of practices included under the topic Restrictive Trade Practices is as follows: price fixing, tying, market division, output restraints, market sharing, eliminating competitors, bid rigging, and supply refusal. See Appendix Table Al.

${ }^{38}$ Some commentators have urged precisely this policy for developing countries, especially Latin America. See Malcolm B. Coate et al., Antitrust in Latin America: Regulating Government and Business, 24 U. MIAMI INTER-AM. L. REv. 37, 81 (1992). 
One empirical question immediately suggested is whether countries with competition laws focused primarily on cartel practices perform better in economic terms than other countries. Dominance law has been an uncertain and controversial affair, at least if judged by the U.S. experience. Judge Posner, relatively early in his career as a scholar, suggested that the uncertainties of dominance law were so daunting that Section 2 of the Sherman Act should be repealed. ${ }^{39}$ And it has been a well-known if not openly acknowledged policy of Republican administrations since Reagan to shift antitrust enforcement toward horizontal agreements and away from unilateral conduct by dominant firms. The variation in international laws may permit researchers to determine whether the evidence on economic performance would support such a shift.

The weakest regions in terms of regulation of anticompetitive agreements are Africa, South America, and Middle East/North Africa. NonEU Europe is relatively weak, with a restrictive trade practices score that is roughly similar to that of Africa. Asia has stronger cartel laws than nonEU Europe.

In the area of cartel regulation, there is a substantial difference between EU and non-EU Europe, whether one looks at EU law or the national statutes. Based on EU law, the EU region's cartel net is roughly 75 percent larger than that of non-EU Europe. Based on national statutes, the difference is 13 percent. Non-EU Europe includes several countries from southeastern Europe and some former Communist regimes. As relatively poor countries, they have not devoted significant resources to competition law. The puzzle is why this difference would be most apparent with respect to cartel regulation and not in the area of dominance law.

\section{Merger Law}

The Merger Score attempts to measure the size of the competition law net applied to mergers (Figures 9 and 10). It is the sum of the scores for two parts of each country's merger law; the part governing merger notification requirements and the part governing the assessment of mergers. It excludes points assigned to defenses, such as efficiency or public-interest defenses. The countries with mandatory-premerger notification requirements tend to have the highest merger scores.

Most of the Merger Scores follow expected patterns. The EU region is the most restrictive regime, based on EU law, and third in rank on the basis of national statutes. The score for the EU region based on EU law

${ }^{39}$ Richard A. Posner, Antitrust Law: An Economic Perspective 214-16 (1976). 
is 7, while the score for the EU region based on national statutes is 5.8 , a relatively small difference in scores. This difference reflects the fact that many EU nations already have mandatory premerger notification regimes. EU law does not introduce significant burdens for big firms that they would face under the national statutes.

Surprisingly, Middle East/North Africa is the second-strongest regime on merger law. The reason for this strong showing is that among the countries in this category-Algeria, Israel, Morocco, Jordan, and Tunisiaall except Tunisia have mandatory-premerger notification regimes. North America is third in rank.

South America appears, again, as the weakest regime. This result occurs because mandatory premerger notification regimes are relatively rare in South America. Of the nine countries in this category (Bolivia, Chile, Paraguay, Peru, Uruguay, Venezuela, Argentina, Columbia, Brazil), only two (Argentina and Columbia) have mandatory-premerger notification requirements. Six of the nine (Bolivia, Chile, Paraguay, Peru, Uruguay, and Venezuela) have no merger notification requirements at all.

Africa is among the weaker regimes, but it is the strongest of the relatively weak merger law regimes. Merger law in Africa is more demanding than that on average in Asia, Oceania, Central America, Caribbean, and South America. Again, this result is a bit of an anomaly given that merger control is an activity that one would assume to be on the low end of priorities for developing countries. Africa's merger score may reflect a tendency, viewed critically by development economists, such as P.T. Bauer, for African countries to adopt relatively interventionist laws in comparison to other countries at comparable stages of economic development. In Bauer's view this tendency was an important obstacle to Africa's development. ${ }^{40}$

40 P.T. Bauer, Reality and RHETORIC: Studies in the ECONOMics OF DEvelopment 27-35 (1984). More recently, the risk that interventionist laws could retard development has been raised in the context of competition laws adopted by transition economies. See Paul E. Godek, A Chicago-School Approach to Antitrust in Developing Nations, 43 ANTITRUST BuLl. 261 (1992); William E. Kovacic, Institutional Foundations for Economic Legal Reform in Transition Economies: The Case of Competition Policy and Antitrust Enforcement, 77 CHI.-KeNT L. REv. 276 (2001); Armando E. Rodriguez \& Malcolm B. Coate, Limits to Antitrust Policy for Reforming Economies, 18 Hous. J. INT'L L. 311 (1996). 
Merger Score

(Averages by Region)

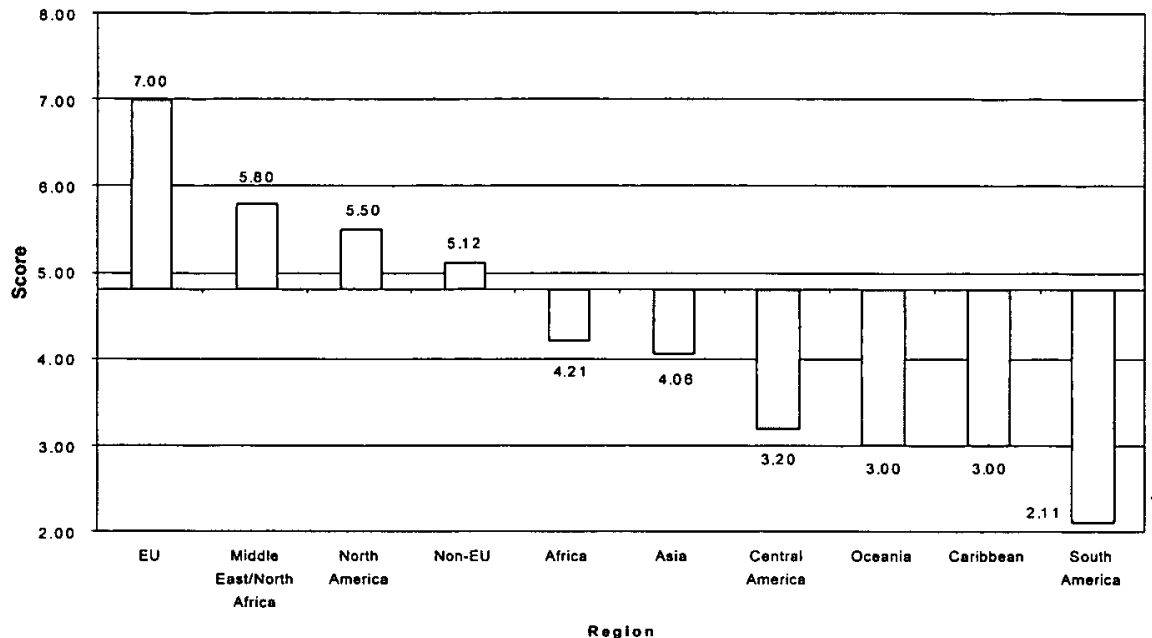

Figure 9. Merger Score (EU law)

Merger Score

(Averages by Region)

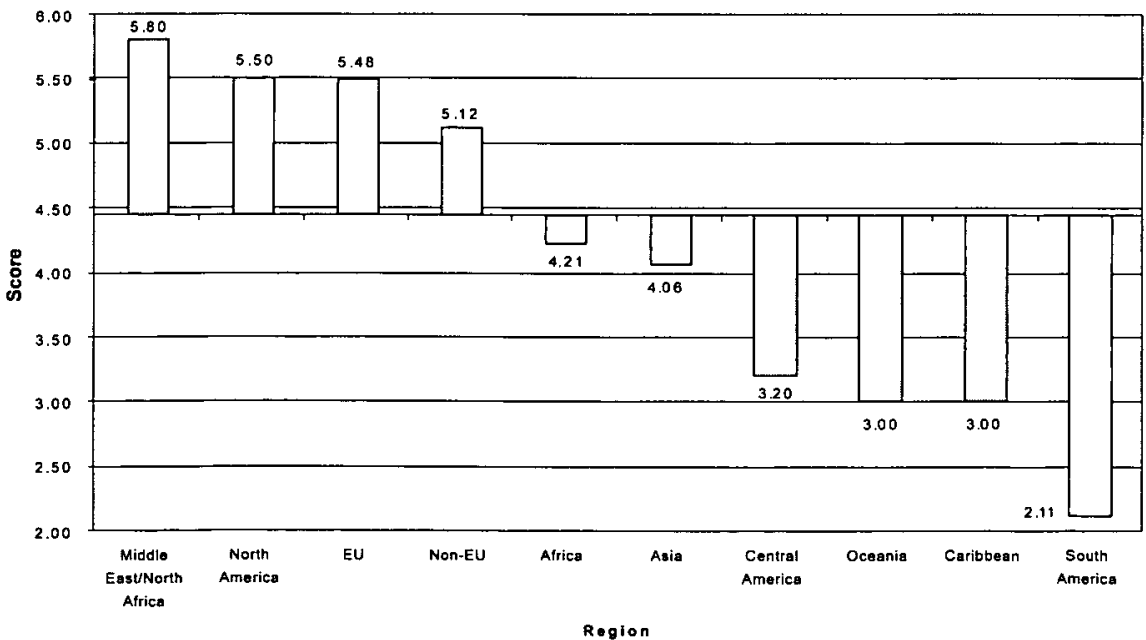

Figure 10. Merger Score (national laws) 
Remedy Score

(Averages by Region)

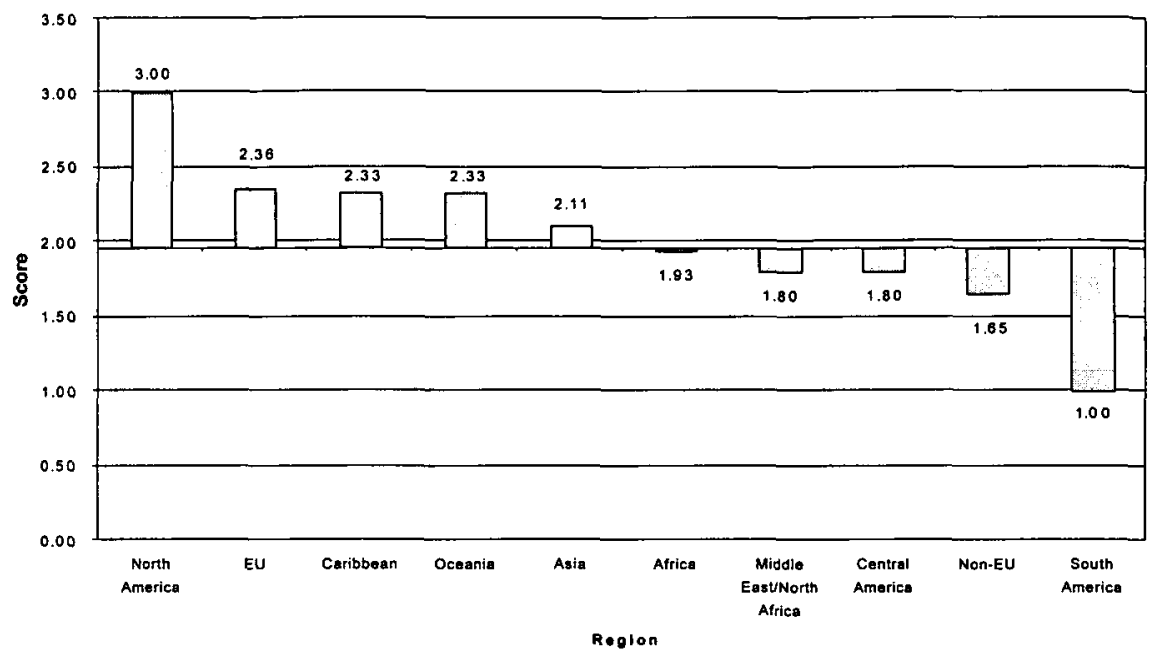

Figure 11. Remedy Score (EU law)

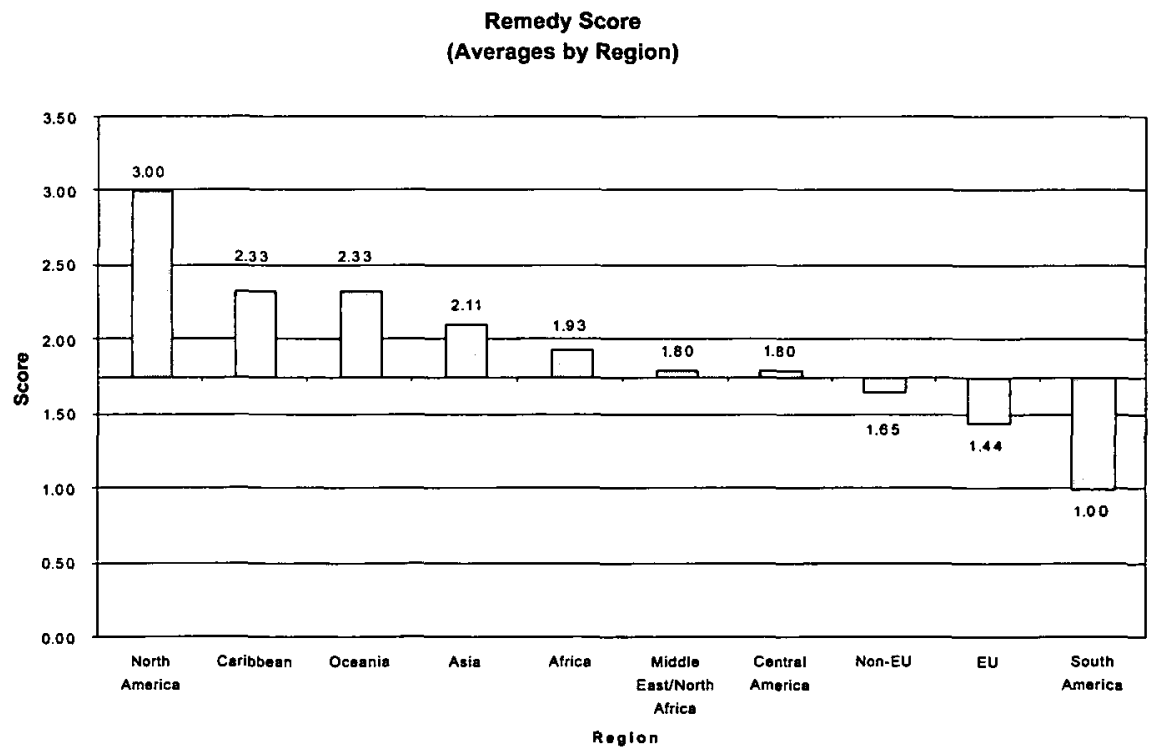

Figure 12. Remedy Score (national laws) 


\section{Remedies}

In addition to substantive law, competition law regimes can be ranked in terms of the penalties applied to firms. The Remedy Score, shown in Figures 11 and 12, is an index measuring the range of punishments available to competition law enforcement authorities. Three types of punishment are considered here: fines, prison sentences, and divestiture orders. The highest score that a country can get is 3 ; the lowest is obviously 0 .

North America is the strongest regime with an average of 3 . South America is the weakest regime, with an average of 1 . The world average is represented by Central American and Middle East/North Africa, with scores of 1.8 .

The dual system of EU law is evident in the remedy comparisons. When EU law is taken into account, the EU region is second in rank following North America. When national laws are consulted, the EU region is one of the weakest regimes. This result implies that the rate of competition law violations should be considerably higher among smaller firms in the European Union that escape the jurisdiction of the European Commission.

Even if we evaluate the EU region on the basis of EU law rather than the national statutes, it is arguably further behind North America than is suggested by the Remedy Scores. The reason is that the European Union does not provide for prison sentences. The only reason the EU score is above 2 in Figure 11 is because some of the member states have statutes that provide for prison sentences and EU law allows for the penalty to be applied under a more rigorous national statute.

Prison sentences are probably frightening to executives of large firms. They present a risk that, at the least, a highly compensated officer will lose his income for a period of years and find it difficult to be reintegrated into the business world after his release. Given these risks, the difference between EU and North American law should be viewed as quite significant.

\section{Efficiency Defenses}

Up to this point we have considered regional comparisons of prohibitions and penalties set out in competition laws. Now we consider efficiency defenses. Efficiency defenses appear in the laws governing merger assessment, restrictive trade practices, and dominance. The three sets of efficiency defenses are grouped together in Figures 13-16. 
Some patterns can be discerned. The regional patterns suggest that the countries that offer efficiency defenses as part of dominance law also offer efficiency defenses as part of their merger laws. North America is most generous in its efficiency defenses, both in merger law and in dominance law. The European Union, on the other hand, is stingy, at least in comparison to North America. In terms of EU law, the EU region does offer an efficiency defense for mergers. However, in terms of national laws, the European Union is relatively stingy in offering efficiency defenses for dominant and merging firms. Indeed, the stinginess with respect to efficiency defenses appears to be a pan-European trait: non-EU Europe is also stingy in offering such defenses for merging and dominant firms.

It makes intuitive sense that the countries that are willing to consider efficiency defenses in actions against dominant firms will also consider such defenses in merger disputes. The issues are similar. In the United States, Sherman Act Section 2, which governs dominant firms, and Clayton Act Section 7, which governs mergers, could both be used by a litigant in an attempt to prevent or reverse a merger. Given the similar concerns in dominance and merger law, it would appear inconsistent for a competition authority to take efficiency defenses into account in one area and not in the other. Most countries appear to follow a consistent pattern of being relatively generous or stingy in efficiency defenses for both parts of the law. The one unusual case is Asia, which is relatively generous in efficiency defenses for merger cases and stingy in efficiency defenses for dominant firms.

The consistent patterns that one should expect to observe in dominance and merger law should not necessarily appear in restrictive trade practices law. A legal system might provide several efficiency defenses for dominant firms without providing the same number for cartels, as the U.S. law illustrates. Indeed, the standard argument in the United States for offering fewer efficiency defenses for restrictive trade practices-and collusive agreements especially-is that they tend as a class to be more consistently harmful to economic welfare. ${ }^{41}$ Given this, it is reasonable to infer, in the absence of countervailing evidence, that an anticompetitive agreement does not have an efficiency basis; and given this inference, it may be efficient to limit the scope for efficiency defenses for anticompetitive agreements.

${ }^{41}$ The list of restrictive trade practices includes tying, which complicates our argument a bit. Although tying was traditionally viewed by U.S. courts as a practice that could not be justified on consumer welfare grounds, see, e.g., Standard Oil Co. of California v. United States (Standard Stations), 337 U.S. 293, 305-06 (1949) (holding that tying agreements serve hardly any purpose beyond the suppression of competition), the law now is recognizing that there are efficiency defenses for tying. 
North America and Oceania are the most generous in terms of efficiency defenses for restrictive trade practices, with EU Europe closely behind. South America is by far the least generous in terms of efficiency defenses for restrictive trade practices.

One might argue that the result for South America is simply an artifact of the earlier data on prohibitions. If a region is relatively weak in prohibitions, then it should obviously be weak in terms of defenses to those prohibitions. The problem with this argument is that a weak law with no defenses can still pose substantial risks to potential defendants, especially if the prohibitive part of the law is general in character. A very limited set of general prohibitions coupled with few or no defenses could easily put potential defendants in a position in which they are unable to predict whether a given course of conduct violates the law. Such a regime gives a troubling degree of discretion to enforcement authorities. A riskaverse potential defendant might prefer to conduct business in a regime with more prohibitions coupled with a larger set of defenses.

Merger Efficiency Defense Score

(Averages by Region)

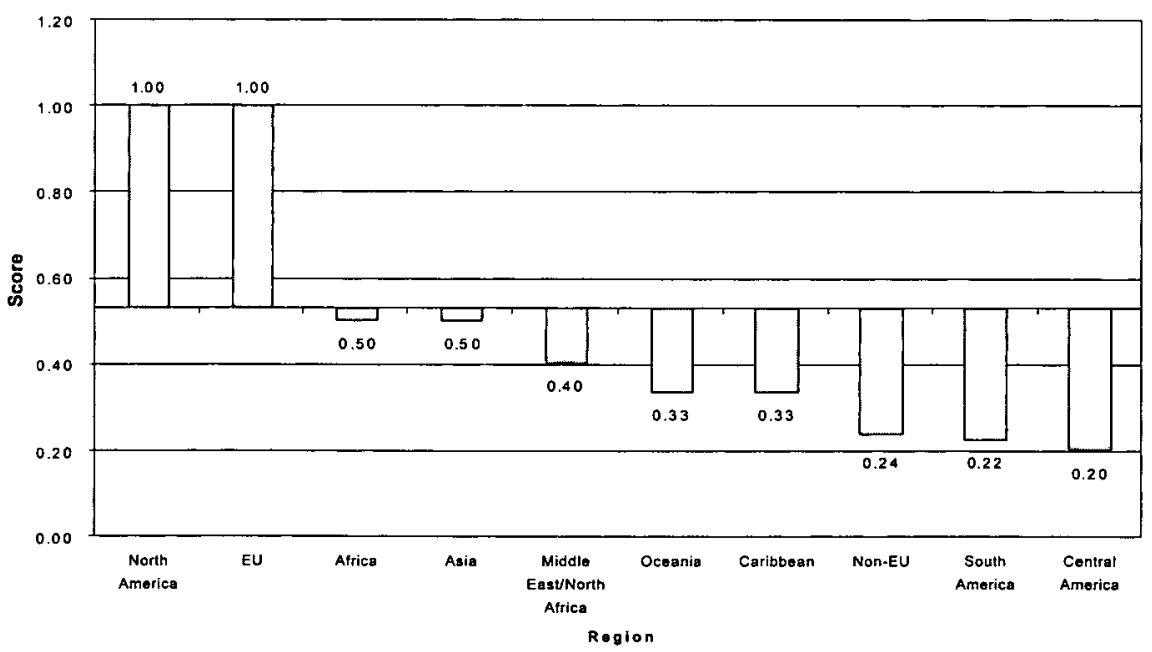

Figure 13. Merger Efficiency Defense (EU law) 
Merger Efficiency Defense Score

(Averages by Region)

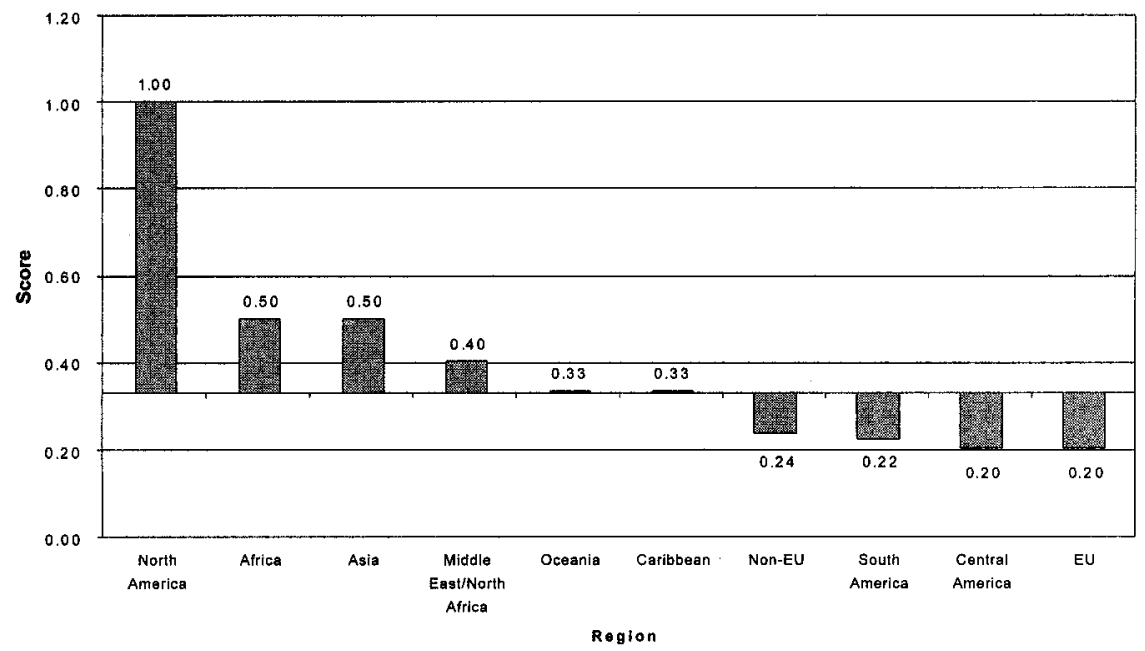

Figure 14. Merger Efficiency Defense (national laws)

Dominance Efficiency Defense Score

(Averages by Region)

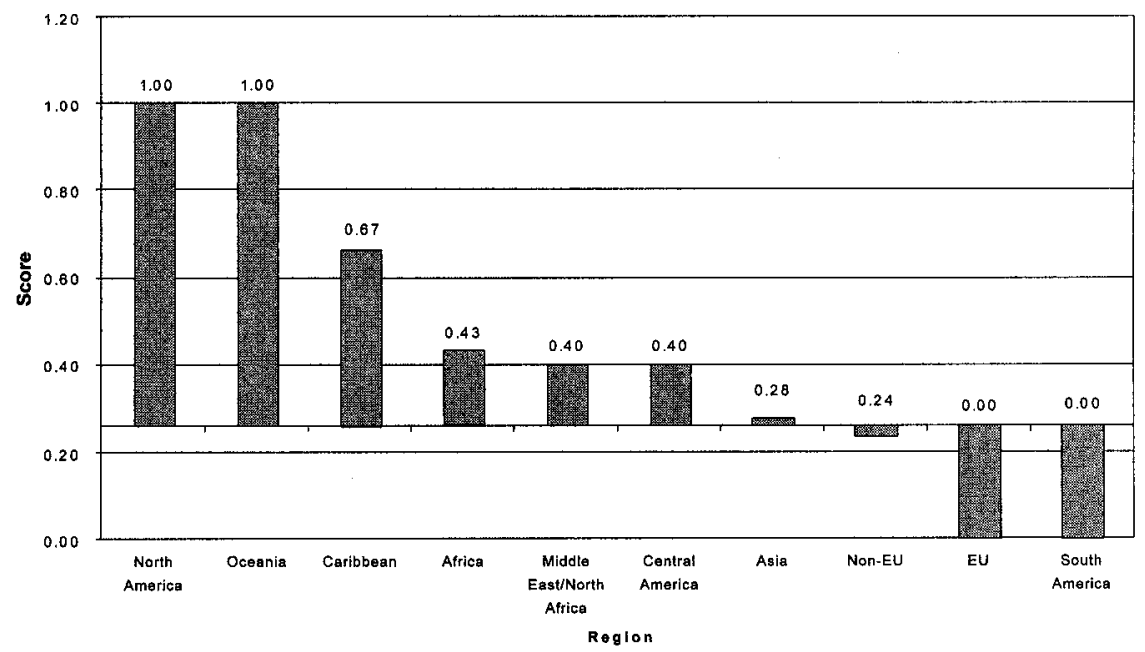

Figure 15. Dominance Efficiency Defense (EU law) 
Restrictive Trade Practices Efficiency Defense Score

(Averages by Region)

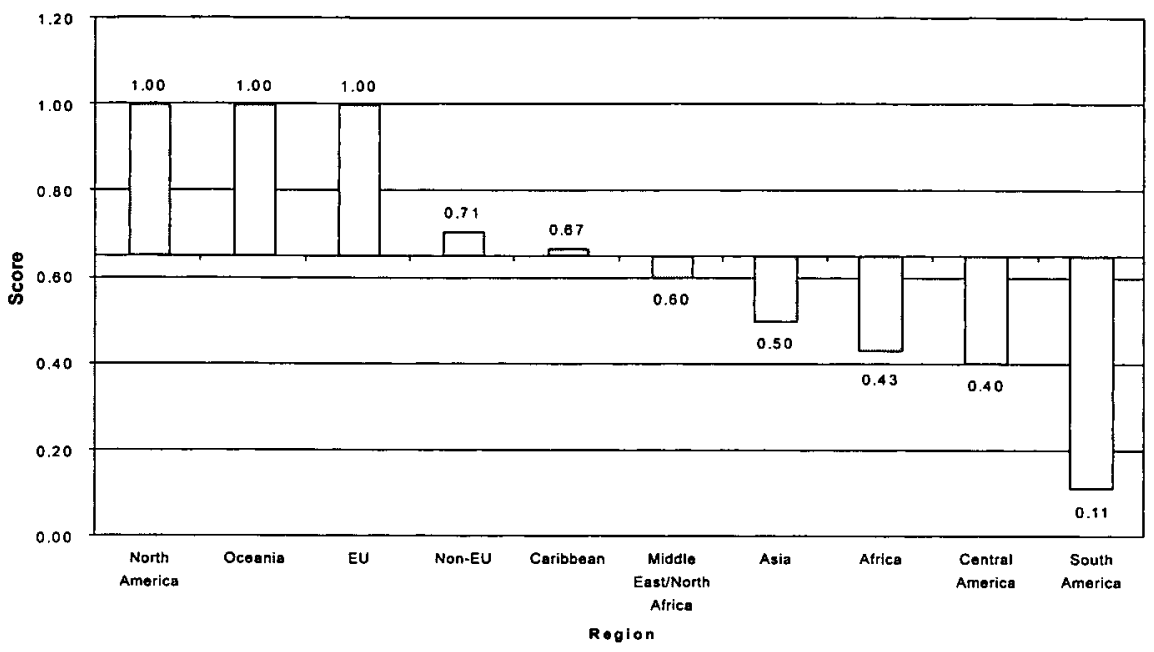

Figure 16. Restrictive Trade Practices Efficiency Defense (EU law)

\section{EMPIRICAL ANALYSIS OF EFFECTS}

Does the presence of a competition law have an impact on the competitiveness of a nation's economy? One way to answer this question is to use regression analysis to see if the presence of a competition law appears to have a statistically significant impact on some measure of competitiveness. Several recent studies have studied this dynamic, using either a single dummy variable to indicate the presence of a competition statute ${ }^{42}$ or survey-based measures of competition law..$^{43}$

The information we have coded on competition law regimes provides a richer measure of competition law. The Scope Index allows us to use a quantitative measure of the law that tracks the restrictiveness of a country's competition statute. Unlike previous studies, our approach uses an objective measure of the size of the competition law net. ${ }^{44}$

42 See Mikyung Yun et al., supra note 14; Hoekman \& Kee, supra note 4.

${ }^{43}$ Krakowski, supra note 4; Voigt, supra note 4.

${ }^{44}$ Perhaps the closest study to this one is Voigt, supra note 4 . Voigt uses a sophisticated survey measure of competition law. The surveys were completed by competition authorities in many countries. One question generated by Voigt's approach is whether a sample heavily weighted with survey evidence from competition authorities might bias the regression results. If competition authorities tend to exist only in the countries that are relatively competitive, a regression analysis that shows that competition law (as described by 


\section{A. Theoretical BACKgROUND}

To many economists, the Lerner Index, ${ }^{45}$ which measures the percentage mark-up of a firm's price over marginal cost at the profit-maximizing production level, provides a desirable theoretical measure of a firm's market power. For this reason, it also serves as an index of the competitive intensity of the market in which the firm operates. If the firm faces few competitors, it will be relatively unconstrained by competition and will charge a price that is close to the monopoly price. On the other hand, if the firm faces many competitive constraints, it will be forced to charge a price that is close to marginal cost. In the standard monopoly model, the Lerner index is

$$
L=\frac{p-m c}{p}=\frac{1}{\varepsilon_{d}},
$$

where $p$ represents price and $m c$ represents marginal cost (at the profitmaximizing level of output) and $\varepsilon_{d}$ is the elasticity of demand for the firm's product.

An alternative to the standard monopoly model is the Cournot model of competition, which examines the profit-maximizing output choices of firms when they face competition from rivals. The Cournot model is mathematically more complicated than the standard monopoly model. For our purposes, however, the model's implications for the Lerner Index are all that is necessary. Suppose there are $N$ firms and the inverse demand curve for the good produced by those firms is $p=a-b Q$, where $Q$ is the sum of the output levels of the $N$ firms (i.e., $Q=q_{1}+\ldots+q_{N}$ ). Suppose, in addition, each firm produces with a simple cost function $C=c q_{i}, i=1, \ldots, N$. In this version of the Cournot model with $N$ firms, the price-cost markup for a given firm is ${ }^{46}$

$$
\frac{p-m c}{p}=\frac{a-c}{a+N c} .
$$

authorities) tends to improve some objective measure may suffer from sample selection bias. Rather than relying on evidence directly from authorities, our study attempts to code information from all of the competition statutes around the world. Another fairly close study in terms of methodology is Krakowski, supra note 4. The Krakowski study relies on the World Economic Forum's survey measures of the intensity of local competition and for the effectiveness of antitrust policy. He finds that the perceived effectiveness of antitrust policy is associated positively with the perceived intensity of competition. In this study, we have avoided using survey measures as both dependent and independent variables, for reasons explained in the text accompanying notes 54-56.

${ }^{45}$ Abba P. Lerner, The Concept of Monopoly and the Measurement of Monopoly Power, 1 REV. ECON. STUD. 157, 157-75 (1934).

46 See, e.g., Michael D. Intriligator, Mathematical Optimization and Economic THEORY 207-09 (1971). 
Treating the price-cost markup as a proxy for competition intensity, this equation suggests that competition intensity is determined by the factors that influence: (1) the level of aggregate demand (represented by the demand shift parameter $a$ ), (2) production costs $(c)$, and (3) the number of firms serving the market $(N)$.

The empirical analysis conducted below takes the competition intensity equation (1) as the theoretical foundation for the regression models employed. The model specifications reflect our attempts to use variables that influence aggregate demand, production costs, or the number of firms serving the market. The one additional factor that we introduce into the model is the law. The Scope Index measure is included as an explanatory variable, on the theory that competition intensity should increase as the scope of the competition law expands.

The basic regression model in this study assumes that the intensity of competition in a nation's economy is influenced by the scope of competition law as well as other factors. Using the Cournot framework as the starting point, the basic model will therefore have the following form

$$
C I=\beta_{I} S I+\beta_{2} a+\beta_{3} c+\beta_{4} N .
$$

$C I$, the dependent variable, is a proxy for the intensity of competition in a nation's economy. The variable $S I$ is the Scope Index. If we assume that $C I$ increases with the intensity of competition, then any variable that causes the market to become more competitive likely reduces the pricecost markup and increases $C I$. If an increase in the scope of a nation's competition law leads to a more competitive economy, the estimated value of $\beta_{1}$ will be positive in our regressions. The Cournot model implies $\beta_{2}$ is positive, $\beta_{3}$ is negative, and $\beta_{4}$ is negative.

The intensity of competition within a country cannot be observed or measured directly. Given this limitation, we use surveys and other measures as proxies. As the aggregate demand shift parameter $a$ and the cost parameter $c$ cannot be directly observed, we use variables that proxy for them. In addition, we use variables that impact entry, exit, and foreign competition to account for the number of firms serving the market.

Because the Cournot model parameters cannot be observed directly and will therefore have to be represented, in a sense, by variables that influence them, it is not straightforward to derive the implications of the Cournot model for the signs of the regression coefficients. To take an example, suppose we use GDP per capita as a variable that influences the demand shift parameter $a$. GDP per capita also influences the number of firms that will enter, as a wealthier economy will attract more sellers of goods. Thus, the impact of GDP per capita in a regression analysis will 
reflect countervailing influences: increasing prices by lifting demand and reducing prices by encouraging entry of firms. Because of these countervailing effects, we make no effort to predict the signs of regression coefficients for the variables that we use to proxy for the Cournot model parameters.

\section{B. BASIC MOdel}

The simplest regression model, which we examine in this part, treats the scope of a nation's competition law as if it were independent of the intensity of competition in the nation's economy. In other words, causation is assumed to run only one way: from the law to the intensity of competition. The model assumes that increasing the scope of the law causes competition among firms in the economy to become more intense. The reason for this assumption is that a broader set of competition laws restrains conduct with anticompetitive effects (e.g., collusion, monopolization, mergers toward monopoly). Of course, as we discuss later, this assumption of one-way causation may be incorrect.

Results for the basic model appear in Tables 2 through 4 . We used two variables as proxies for the notional dependent variable, the intensity of competition. One is a survey measure of the intensity of local competition, compiled by the World Economic Forum. The intensity of competition survey measure runs from 1 (not intense) to 7 (intense). Because of the subjective nature of this measure, we refer to it as the perceived intensity of competition. The other proxy is the Purchasing Power Parity index, which we use below as an objective measure of the intensity of competition.

The key independent variables are the Scope Index (based on national competition codes), GDP per capita, the log of population, the average wage in the manufacturing sector, government spending as a percentage of GDP, the competition enforcement budget as a percentage of GDP, and the number of years that the nation has had a competition law. The table also includes a dummy variable that indicates whether the country has a competition agency.

As noted, we have used the Scope Index based on national competition statutes. This approach matters only in the case of EU Europe, because EU Europe is a much stronger regime if the law is coded on the basis of the EU provisions. However, the national statutes offer richer variation in the Scope Index measure and provide at least a minimal and arguably more accurate measure of the scope of the competition law in a particular EU country. 


\section{Subjective Measure of Competition Intensity as Dependent Variable}

\section{a. Competition Law Effect}

The most important variable in this study is the Scope Index, our measure of the size of the competition law net. Our first table of results, Table 2, presents regression results using the World Economic Forum's survey measure of the intensity of competition for the years 2003 and 2004 pooled. ${ }^{47}$

There is evidence in Table 2 that the size of the competition law net is associated with greater intensity of competition-at least as reflected in the World Economic Forum's survey measure. The estimates of the Scope Index coefficient are statistically significant and range from a low of .018 to a high of .023 . The estimates suggest that for every one-point increase in the Scope Index, the Competition Intensity survey measure increases by .02 .

To consider a concrete example of the implications of these results, take the case of Peru, which has a Scope Index of 13 and a Competition Intensity measure of 4.7 for 2003. Although, as a general rule, regression results should be considered useful only for small extrapolations, let us consider a relatively large extrapolation, recognizing that the answer is most likely an overstatement. Suppose Peru were to revamp its competition statute, so that the Scope Index increases by 5 points to a new score of 18. The results of Table 2 suggest that the maximum increase in the Competition Intensity measure that would result is 0.1 . In other words, a five-point increase in the Scope Index could increase the Competition Intensity measure from 4.7 to 4.8 .

In terms of statistical significance, the results of Table 2 are largely supportive of the claim that the scope of a nation's competition law is positively associated with the intensity of competition in its economy. Of course, there is also the question of economic significance. Even if we view the results as indicating a statistically significant marginal impact of .02 for the Scope Index, this result may fall below what some observers would consider an economically significant impact. Return to the example of Peru. Suppose, somewhat fantastically, Peru were to overhaul its

\footnotetext{
${ }^{47}$ Estimating the years separately yields results similar to those reported in the table. Also, including dummy variables for regions does not change the results. We do not consider the sample to have sufficient variation (especially in the Scope Index) to make a fixed effects regression useful at this stage. As the sample is expanded, fixed effects regressions should look more promising.
} 
Table 2

Competition Intensity Regressions, Years 2003 and 2004 Pooled

\begin{tabular}{|c|c|c|c|c|c|}
\hline $\begin{array}{l}\text { Dependent Variable: } \\
\text { Competition Intensity }\end{array}$ & Reg. 1 & Reg. 2 & Reg. 3 & Reg. 4 & Reg. 5 \\
\hline $\begin{array}{l}\text { Independent } \\
\text { Variables: }\end{array}$ & $\begin{array}{l}\text { Coefficient } \\
\text { (It-statl) }\end{array}$ & & & & \\
\hline Constant & $\begin{array}{c}1.95 \\
(3.99)\end{array}$ & $\begin{array}{c}1.74 \\
(3.35)\end{array}$ & $\begin{array}{c}2.62 \\
(4.45)\end{array}$ & $\begin{array}{c}2.03 \\
(4.10)\end{array}$ & $\begin{array}{c}2.71 \\
(3.83)\end{array}$ \\
\hline Scope Index & $\begin{array}{c}.023^{* * * *} \\
(4.27)\end{array}$ & $\begin{array}{c}.018 * * * \\
(3.36)\end{array}$ & $\begin{array}{c}.022 * * * \\
(3.08)\end{array}$ & $\begin{array}{c}.019 * * * \\
(2.89)\end{array}$ & $\begin{array}{l}.019^{* *} \\
(1.92)\end{array}$ \\
\hline GDP Per Capita & $\begin{array}{c}.00002 * * * \\
(4.46)\end{array}$ & $\begin{array}{c}.00002^{* * *} \\
(4.15)\end{array}$ & $\begin{array}{c}.00002^{* * *} \\
(2.67)\end{array}$ & $\begin{array}{c}.00002 * * * \\
(4.05)\end{array}$ & $\begin{array}{c}.00002 * * * \\
(3.20)\end{array}$ \\
\hline Imports $\div G D P$ & $\begin{array}{l}.008 * * * \\
(4.31)\end{array}$ & $\begin{array}{c}.008 * * * \\
(4.63)\end{array}$ & $\begin{array}{l}.006 * * * \\
(2.71)\end{array}$ & $\begin{array}{c}.008 * * * \\
(4.03)\end{array}$ & $\begin{array}{l}.005^{* * *} \\
(2.27)\end{array}$ \\
\hline Log Population & $\begin{array}{c}.106^{* * * *} \\
(3.88)\end{array}$ & $\begin{array}{c}.116^{* * *} \\
(4.23)\end{array}$ & $\begin{array}{l}.077 * * * \\
(2.29)\end{array}$ & $\begin{array}{l}.102^{* * * *} \\
(3.71)\end{array}$ & $\begin{array}{l}.077^{* * * *} \\
(2.16)\end{array}$ \\
\hline $\begin{array}{l}\text { Age of Competition } \\
\quad \text { Law }\end{array}$ & $\begin{array}{c}.006 * * * \\
(2.12)\end{array}$ & $\begin{array}{c}.006^{* * *} \\
(2.22)\end{array}$ & $\begin{array}{l}.006^{* *} \\
(1.88)\end{array}$ & $\begin{array}{c}.005^{* * *} \\
(2.04)\end{array}$ & $\begin{array}{c}.004 \\
(1.63)\end{array}$ \\
\hline $\begin{array}{l}\text { Government } \\
\text { Consumption } \\
\quad \div \text { GDP }\end{array}$ & & $\begin{array}{c}.008 \\
(1.04)\end{array}$ & & & \\
\hline Average Wage & & & $\begin{array}{l}.002 \\
(.70)\end{array}$ & & $\begin{array}{l}.001 \\
(.61)\end{array}$ \\
\hline $\begin{array}{c}\text { Competition } \\
\text { Agency }\end{array}$ & & & & $\begin{array}{l}.096 \\
(.83)\end{array}$ & \\
\hline $\begin{array}{l}\text { Enforcement Budget } \\
\quad \div G D P\end{array}$ & & & & & $\begin{array}{r}11.98 \\
(1.32)\end{array}$ \\
\hline Adj R-squared & .45 & .46 & .41 & .45 & .37 \\
\hline Prob $>$ F & 0.0000 & 0.0000 & 0.0000 & 0.0000 & 0.0000 \\
\hline $\mathbf{N}$ observations & 169 & 168 & 104 & 167 & 75 \\
\hline
\end{tabular}

Notes: ${ }^{* * *}$ for variables that are at 5 percent significance level are italic; ${ }^{* *}$ for those at 10 percent significance level.

competition laws to raise the Scope Index from 13 to one of the highest scores possible, 28. Such a large increase in the scope of Peru's competition laws would, these results suggest, increase Peru's Competition Intensity measure in 2003 from 4.7 to 5 . This change is of course a substantial increase, given that the Competition Intensity measure runs from 1 to 7 . But in terms of its overall rank among competitive economies, 
Peru would remain far below the most intensively competitive economies (e.g., United States, Hong Kong, Germany, United Kingdom). ${ }^{48}$

In addition to our measure for the scope of the competition laws, we have also included a variable measuring the number of years the competition law has been effect (in some form), ${ }^{49}$ a variable measuring the competition law enforcement budget as a percentage of GDP, and a dummy variable indicating the existence of a competition law enforcement agency.

The purpose of the Age of Competition Law variable is to capture the extent to which a culture of enforcement may have developed. A nation that has had a competition law for 100 years is likely to have a different view toward enforcement than a nation that has had a competition law for only five years. The results suggest that the law's age has a significant impact. The larger estimates suggest that each year the law has been in effect increases the competition intensity survey measure by nearly .01 . Taking .01 as an upper bound, this result suggests that it would take quite a long time, perhaps a century or more, for a competition law to move a country up one digit in the survey measure of competition intensity. ${ }^{50}$

We included two enforcement measures in the regression. The variable measuring enforcement budget relative to GDP was included in order to see whether countries that spend more on competition, relative to the size of the economy, have better results in terms of the intensity of competition. The other enforcement variable is a dummy variable indicating the existence of a competition agency. Both enforcement variables fail to show a statistically significant impact.

\section{b. Other Variables}

In addition to measures of competition law, such as the scope of the competition statute and its age, several other variables used in the regres-

\footnotetext{
48 Specifically, Peru would move from 46th place to 36 th place based on the 2003 WEF's Competition Intensity survey results.

${ }^{49}$ As the American experience suggests, a competition law may have been in effect for many years, and yet the law may have changed substantially over that period. Competition laws in particular are almost always in a process of revision. The Age of Competition Law variable in our regressions measures the age of the statute from the enactment date of its key parts. For example, the U.S. competition law's age is measured from 1890, the enactment year of the Sherman Act. No effort has been made' to incorporate significant changes, such as the enactment of additional legislation (e.g., the 1914 Clayton Act).

${ }^{50}$ See Krakowski, supra note 4, which discusses learning curve effects. If learning effects dampen as the time increases, then the marginal impact of an additional year after having a law for ten years is smaller than that of the additional year after having a law for five years.
} 
Table 3

Purchasing Power Parity Regressions, Years 2003 and 2004 Pooled

\begin{tabular}{lccc}
\hline $\begin{array}{l}\text { Dependent Variable: } \\
\text { Log PPP }\end{array}$ & Reg. 1 & Reg. 2 & Reg. 3 \\
\hline Independent & Coefficient & & \\
Variables: & $($ It-statl) & & \\
Constant & 3.93 & 4.41 & .025 \\
& $(1.88)$ & $(1.28)$ & $(.01)$ \\
Scope Index & -.022 & .04 & -.04 \\
& $(1.09)$ & $(1.07)$ & $(1.56)$ \\
GDP per capita & $-.00005^{* * *}$ & -.00003 & $-.00007^{* * *}$ \\
& $(2.31)$ & $(.94)$ & $(2.85)$ \\
Imports $\div$ GDP & -.009 & -.004 & -.012 \\
& $(1.27)$ & $(.35)$ & $(1.47)$ \\
Log Population & .108 & -.047 & $.272^{* * *}$ \\
& $(.95)$ & $(.25)$ & $(2.54)$ \\
Age of Competition Law & -.01 & .002 & -.012 \\
& $(.74)$ & $(.15)$ & $(.92)$ \\
Government Consumption $\div$ GDP & $-.102^{* * *}$ & $-.104^{* * *}$ & \\
Average Wage & $(3.81)$ & $(2.02)$ & \\
Competition Agency & & -.015 & \\
Adj R-squared & & $(.61)$ & \\
Prob > F & & & .169 \\
\hline N observations & .18 & .11 & $(.35)$ \\
\hline & 0.0000 & 0.0595 & 0.0000 \\
\hline
\end{tabular}

Notes: $* * *$ for variables that are at 5 percent significance level are italic; $* *$ for those at 10 percent significance level.

sions in Tables 2 and 3 have statistically significant effects on perceived competitive intensity. GDP per capita is positive and statistically significant in each regression..$^{51}$ In particular, each $\$ 1000$ increase in GDP per capita increases the survey measure of competition intensity by roughly .02 .

${ }^{51}$ Recall that the Cournot competition model introduced at the start of this discussion pointed to three determinants of competition intensity: the demand shift parameter, the cost parameter, and the number of firms. GDP per capita probably impacts at least two of these parameters because a wealthier economy will attract more firms and also generate a greater demand for goods. The positive estimate for GDP per capita suggests that 
The $\log$ of population is included as an independent variable in order to control directly for the size of the market, which we assume increases with population. The results, indicating that a 1 percent increase in population is associated with a .1 increase in the perceived intensity of competition measure, show a large impact. As a policy implication, this estimate, coupled with the statistically significant estimate for imports as a percent of GDP, suggests that opening local markets to global competition is the fastest way to increase the perceived intensity of competition.

\section{Objective Measure of Competition Intensity as Dependent Variable}

Table 3 repeats three of the regressions of Table 2, this time using an objective proxy for the intensity of competition, which also permits us to take advantage of a broader sample. In these regressions we use the Purchasing Power Parity index (PPP) from the World Bank's World Development Indicators database. PPP is the exchange rate between currencies that equalizes in value a common basket of consumption items. For example, if a McDonald's hamburger is priced at US $\$ 2.00$ in the United States and GBP 1.00 in Britain, the PPP that equalizes the two currencies (American dollars and British pounds), treating hamburgers as the only item of consumption, is .5.

Since one of the reasons the price of hamburger can be relatively high is local market power, we view PPP as a potential proxy for the intensity of competition. Suppose, for example, that because of an increase in local market power, McDonald's is able to raise the price of its hamburger in Britain from GBP 1.00 to GBP 1.50. The PPP that equalizes dollars and pounds then increases from .5 to .75 .

This example suggests that even though PPP is just an exchange, and for that reason meaningless, ${ }^{52}$ it may still serve as an index that captures to some degree the effects of market power on prices. If the Scope Index measure has a negative and statistically significant impact on PPP, we regard that as evidence that it is increasing the intensity of competition.

the market-expanding effect of increasing national wealth is greater than the demandenhancing effect.

$5^{2}$ Of course, the core of the problem here is that there are no good objective proxies that would allow us to assess competitive intensity across countries. An alternative to using PPP is to use the GDP deflator multiplied by the Purchasing Power Parity index. For this approach see Helmut Ziegelschmidt et al., Product Market Competition and Economic Performance in Australia (OECD Working Paper No. 451, Oct. 2005), available at $\mathrm{http}: / /$ ideas.repec.org/j/K20.html. The GDP deflator is often used to measure relative prices over time within an economy. However, as most publicly available GDP deflator series do not use common base periods, it is unclear that additional accuracy could be gained by using this approach instead of the direct comparison of PPPs. 
As Table 3 shows, however, the scope of the competition law does not have a statistically significant impact on PPP. The sign of the Scope Index coefficient is often negative, suggesting that there may be a procompetitive effect. However, the legal scope measure is statistically insignificant in the regressions (though nearly significant in the last column). The statistical insignificance result is also true for the age of the competition statute.

\section{Assessing Components of the Scope IndeX}

Table 4 breaks down the Scope Index into its key components, which are sub-indexes measuring the scope of the law on restrictive trade practices, the scope of the law on dominance, the scope of merger law, and the scope of enforcement. The enforcement sub-index captures the existence of exterritorial enforcement, the range of remedies, and the scope of private enforcement. Our goal in the first two columns of the table is to see if there is any particular portion of competition law that is associated with greater perceived intensity of competition.

Of the sub-indexes measuring the substantive law-dominance, restrictive trade practices, and mergers-only one, the restrictive trade practices index, yields a statistically significant effect, and that result occurs in only the first regression (which includes an independent variable for government spending as a percentage of GDP but not for whether there is a competition enforcement agency).

The exceptional case in Table 4 is the sub-index for enforcement, which is positive and statistically significant in both of the competition intensity regressions. The results suggest that a one point increase in the enforcement sub-index increases the intensity of competition survey measure by .1. The marginal impact of the enforcement variable is roughly five times that of the overall scope measure, which suggests that enforcement is more important than the scope of the substantive law.

The signs and magnitudes of the sub-indexes suggest a ranking of the major components of competition law in terms of their effectiveness: enforcement, restrictive trade practices, mergers, and dominance. While the estimates suggest that increasing the scope of restrictive trade practices law may enhance perceived competition intensity, increasing the scope of merger or dominance law appears not to offer such a potential gain. Indeed, the first column suggests that increasing the dominance law index reduces the perceived competition intensity.

The remaining columns in Table 4 examine the impacts of the same sub-indexes on our objective proxy for the intensity of competition, the 
Table 4

Regressions Using Components of Competition Law, Years 2003 and 2004 Pooled

\begin{tabular}{|c|c|c|c|c|c|}
\hline $\begin{array}{l}\text { Dependent Variable: } \\
\text { Competition Intensity }\end{array}$ & Reg. 1 & Reg. 2 & $\begin{array}{c}\text { Dependent } \\
\text { Variable: PPP }\end{array}$ & Reg. 3 & Reg. 4 \\
\hline $\begin{array}{l}\text { Independent } \\
\text { Variables: }\end{array}$ & $\begin{array}{l}\text { Coefficient } \\
\text { (It-statl) }\end{array}$ & & & & \\
\hline Constant & $\begin{array}{c}1.81 \\
(3.45)\end{array}$ & $\begin{array}{c}2.27 \\
(4.54)\end{array}$ & & $\begin{array}{c}3.54 \\
(1.66)\end{array}$ & $\begin{array}{l}.077 \\
(.04)\end{array}$ \\
\hline $\begin{array}{l}\text { Restrictive Trade } \\
\text { Practices }\end{array}$ & $\begin{array}{l}.047 * * \\
(1.83)\end{array}$ & $\begin{array}{c}.031 \\
(1.12)\end{array}$ & & $\begin{array}{l}.072 \\
(.60)\end{array}$ & $\begin{array}{c}.187 \\
(1.53)\end{array}$ \\
\hline Dominance & $\begin{array}{l}-.058 \\
(1.54)\end{array}$ & $\begin{array}{r}-.032 \\
(.77)\end{array}$ & & $\begin{array}{l}.037 \\
(.21)\end{array}$ & $\begin{array}{r}-.110 \\
(.94)\end{array}$ \\
\hline Merger & $\begin{array}{l}-.025 \\
(1.22)\end{array}$ & $\begin{array}{r}-.020 \\
(.55)\end{array}$ & & $\begin{array}{r}-.077 \\
(.84)\end{array}$ & $\begin{array}{c}-.155^{* *} \\
(1.68)\end{array}$ \\
\hline Enforcement & $\begin{array}{l}.112 * * * \\
(3.70)\end{array}$ & $\begin{array}{l}.110 * * * \\
(3.32)\end{array}$ & & $\begin{array}{l}-.149 \\
(1.00)\end{array}$ & $\begin{array}{r}-.125 \\
(.82)\end{array}$ \\
\hline GDP Per Capita & $\begin{array}{c}.00002 * * * \\
(3.55)\end{array}$ & $\begin{array}{c}.00002 * * * \\
(3.80)\end{array}$ & & $\begin{array}{c}-.00005^{* * * *} \\
(2.11)\end{array}$ & $\begin{array}{c}-.00006^{* * *} \\
(2.54)\end{array}$ \\
\hline Imports $\div G D P$ & $\begin{array}{l}.008 * * * \\
(4.65)\end{array}$ & $\begin{array}{l}.009 * * * \\
(4.01)\end{array}$ & & $\begin{array}{l}-.009 \\
(1.24)\end{array}$ & $\begin{array}{c}.012 \\
(1.50)\end{array}$ \\
\hline Log Population & $\begin{array}{l}.105^{* * * *} \\
(3.85)\end{array}$ & $\begin{array}{c}.087 * * * \\
(3.14)\end{array}$ & & $\begin{array}{c}.126 \\
(1.08)\end{array}$ & $\begin{array}{c}.267 * * * \\
(2.47)\end{array}$ \\
\hline $\begin{array}{l}\text { Age of Competition } \\
\text { Law }\end{array}$ & $\begin{array}{c}.006 * * * \\
(2.39)\end{array}$ & $\begin{array}{c}.006 * * * \\
(2.18)\end{array}$ & & $\begin{array}{r}-.010 \\
(.80)\end{array}$ & $\begin{array}{l}-.013 \\
(1.02)\end{array}$ \\
\hline $\begin{array}{l}\text { Government } \\
\text { Consumption } \div G D P\end{array}$ & $\begin{array}{l}.016^{* *} \\
(1.92)\end{array}$ & & & $\begin{array}{c}-.095^{* * *} \\
(3.44)\end{array}$ & \\
\hline \multicolumn{6}{|l|}{ Average Wage } \\
\hline Competition Agency & & $\begin{array}{l}.048 \\
(.41)\end{array}$ & & & $\begin{array}{l}.173 \\
(.36)\end{array}$ \\
\hline Adj R-squared & .49 & .47 & & .20 & .15 \\
\hline Prob $>$ F & 0.0000 & 0.0000 & & 0.0000 & 0.0000 \\
\hline $\mathbf{N}$ observations & 168 & 167 & & 275 & 284 \\
\hline
\end{tabular}

Notes: $* * *$ for variables that are at 5 percent significance level are italic; ** for those at 10 percent significance level.

PPP index. Except for the marginally significant estimate for the merger sub-index in the last column, there is no evidence suggesting that any of the sub-indexes reduce prices. The estimated coefficients for the subindexes are for the most part statistically insignificant. 


\section{ENDOGENEITY OF SCOPE INDEX AND INSTRUMENTAL VARIABLES ESTIMATION}

Given the causation and endogeneity issues, briefly discussed in Part IV.B.1, the statistically significant estimates for the Scope Index have to be regarded with some suspicion. The standard approach to estimation in the presence of potential endogeneity bias is to use instrumental variables estimation. In this part, we report instrumental variable estimates of the impact of the Scope Index.

To take a simple illustration of the endogeneity problem, suppose legislators in Zanadu are contemplating the enactment of a competition law or the expansion of the scope of a law already in existence. In legislative debates, opponents might note that competition is already perceived to be intense in Zanadu, and there is, therefore, no need for such a law or expansion of existing law. If the competition law opponents prevailed on the basis of this argument, then the perceived intensity of competition would have impacted the scope of the competition law in Zanadu.

This illustration suggests that the key to finding suitable regressors is to find variables that affect the likelihood of a competition law being enacted or modified and, at the same time, are not influenced by the intensity of competition. These variables would make ideal instrumental variables. Of course, this data is difficult to find in the context of competition law. The goal for this project is to find instruments for the scope of the law variable. This task requires finding variables that satisfy the above requirement and, in addition, are not obvious candidates as regressors in the competition intensity equation.

We have taken instruments from two sources. One is the "legal origin" variables of the "law and growth" literature. ${ }^{53}$ The other source is the WEF's survey tables, which provide additional perception indexes that could serve as instrumental variables.

The legal origin variables indicate whether the legal system in a country has its origins in the English, French, Scandinavian, German, or socialist legal traditions. Legal origin is clearly unaffected by the perceived intensity of competition. Yet, it may have an impact on the likelihood that a country will adopt a competition law, since the tendency toward interventionist policies appears to be influenced by legal origin..$^{54}$

\footnotetext{
${ }^{53}$ Rafael La Porta et al., The Quality of Government, 15 J.L. Econ. \& OrG. 222 (1999).

${ }^{54}$ Id.
} 
The WEF's survey tables also provide indexes that probably track variables that influence the likelihood of adoption or the scope of a competition law. For example, in addition to surveying the intensity of competition, the WEF's tables include indexes measuring perceived favoritism of government to firms, the perceived regional disparity in the economic environment (e.g., infrastructure), and the perceived degree to which government subsidies distort markets. Many of these perceptions probably influence the likelihood that a competition law will be enacted, expanded, or maintained.

Still, the difficulty in using many of the WEF's survey measures is that they are likely to be correlated with the perceived intensity of competition. The same business person who tells a WEF surveyor that competition is not intense in his country also seems likely to think that government plays favorites among firms or distorts the market with subsidies. Although these survey measures may explain the existence of a competition law, they are likely to be correlated with the perceived intensity of competition, the variable we are attempting to explain.

In view of the difficulty of finding plausible instruments, we settled on the legal origin variables and the WEF's survey measure of regional disparity in the economic environment. Regional disparity apparently played some role in the enactment of the Sherman Act in the United States. Boudreaux, DiLorenzo, and Parker argue that farm lobbies seeking protection from the competition of large-scale processing centers in cities played a substantial role in the enactment of U.S. antitrust law. ${ }^{55}$ Moreover, it is plausible that if firms believe that certain advantages attributable to economic environment, such as infrastructure, affect their ability to compete, they will pressure legislators for a competition law.

The instrumental variable regression results appear in Table 5. The first column of Table 5 uses only the legal origin variables as instruments for the Scope Index. The second column uses the legal origin variables and the WEF's index of perceived regional disparity in the quality of the economic environment. Both regressions fail to show a statistically significant impact for the Scope Index.

Of course, these results are equally consistent with the theory that the law's scope does positively impact the intensity of competition, but we have simply failed to find a good set of instruments. ${ }^{56}$ The results of the instrumental variables regressions are inconclusive.

${ }^{55}$ MCChESNEY \& SHUGART, supra note 4, at 255-70.

${ }^{56}$ On the problems generated by using instruments that are weak explanatory variables for the endogenous variables, see John Bound et al., Problems with Instrumental Variables Estimation when the Correlation Between the Instruments and the Endogenous Explanatory Variables Is Weak, 90 J. AM. STAT. Ass'N 443 (1995). 
Table 5

Competition Intensity Instrumental Variable Regressions

\begin{tabular}{lcc}
\hline Dependent Variable: & Reg. 1 & $\begin{array}{c}\text { Reg. } 3 \\
\text { Competition Intensity }\end{array}$ \\
\hline Independent & Coefficient & \\
Variables: & $($ It-statl) & \\
Constant & 1.47 & 1.45 \\
& $(2.56)$ & $(1.66)$ \\
Scope Index & -.004 & -.007 \\
& $(.25)$ & $(.41)$ \\
GDP Per Capita & $.00003^{* * *}$ & $.00003^{* * *}$ \\
& $(6.72)$ & $(6.70)$ \\
Imports $\div$ GDP & $.006^{* * *}$ & $.006^{* * *}$ \\
& $(3.11)$ & $(3.01)$ \\
Log Population & $.149^{* * *}$ & $.152^{* * *}$ \\
& $(4.51)$ & $(4.53)$ \\
Government Consumption & $.02^{* *}$ & $.022^{* * *}$ \\
$\div$ GDP & $(1.75)$ & $(1.85)$ \\
Adj R-squared & .37 & .35 \\
Prob $>$ F & 0.0000 & 0.0000 \\
\hline N observations & 167 & 167 \\
\hline Notes: & & \\
${ }^{1}$ Column 1 uses legal tradition instruments only. & \\
${ }^{2}$ Column 2 uses legal tradition instruments plus the regional disparity survey measure \\
from the WEF (2004).
\end{tabular}

\section{CONCLUSION}

Every empirical study is tentative or provisional in the sense that its results are valid, at best, until the next empirical study upends its conclusions. The same caveat applies here. Empirical researchers will develop better ways to measure the scope of antitrust law and to test its effectiveness in promoting competition than the methods used in this article.

In this article we have presented measures of the scope of competition law and its various components around the globe, such as the laws governing restrictive trade practices and dominance. Given the difficulty of saying anything useful about the laws of 102 countries, we have limited ourselves to regional comparisons. The regional comparisons suggest that for large enterprises "antitrust risk"-the risk of violating some com- 
petition law provision-is substantially higher in the European Union than anywhere else. Antitrust risk is lowest in South and Central America.

Regression analysis of the law's effect yielded mixed results, leaving room for more than one interpretation and clearly indicating a need for more data. Ordinary least squares regressions of the impact of the law's scope suggest that it has a positive impact on perceived competitive intensity-which we find surprising, given the broad economic forces affecting competition intensity. These estimates, however, have to be regarded with suspicion as statements about the impact of the law on the real intensity of competition. Moreover, instrumental variable estimates reported here, although preliminary, fail to show a significant impact for competition law. An attempt to proxy for real competitive intensity also failed to show a significant impact.

There are many questions that could not be addressed within the scope of this article. For example, does the scope of competition law have a positive impact on a nation's wealth? Does the scope of a country's merger law have a substantial impact on the frequency of merger activity within the country? In addition, the results here suggest that the key empirical challenge going forward is obtaining objective measures of the intensity of competition and estimates of the impact of competition statutes that are plausibly free of an endogeneity bias. 


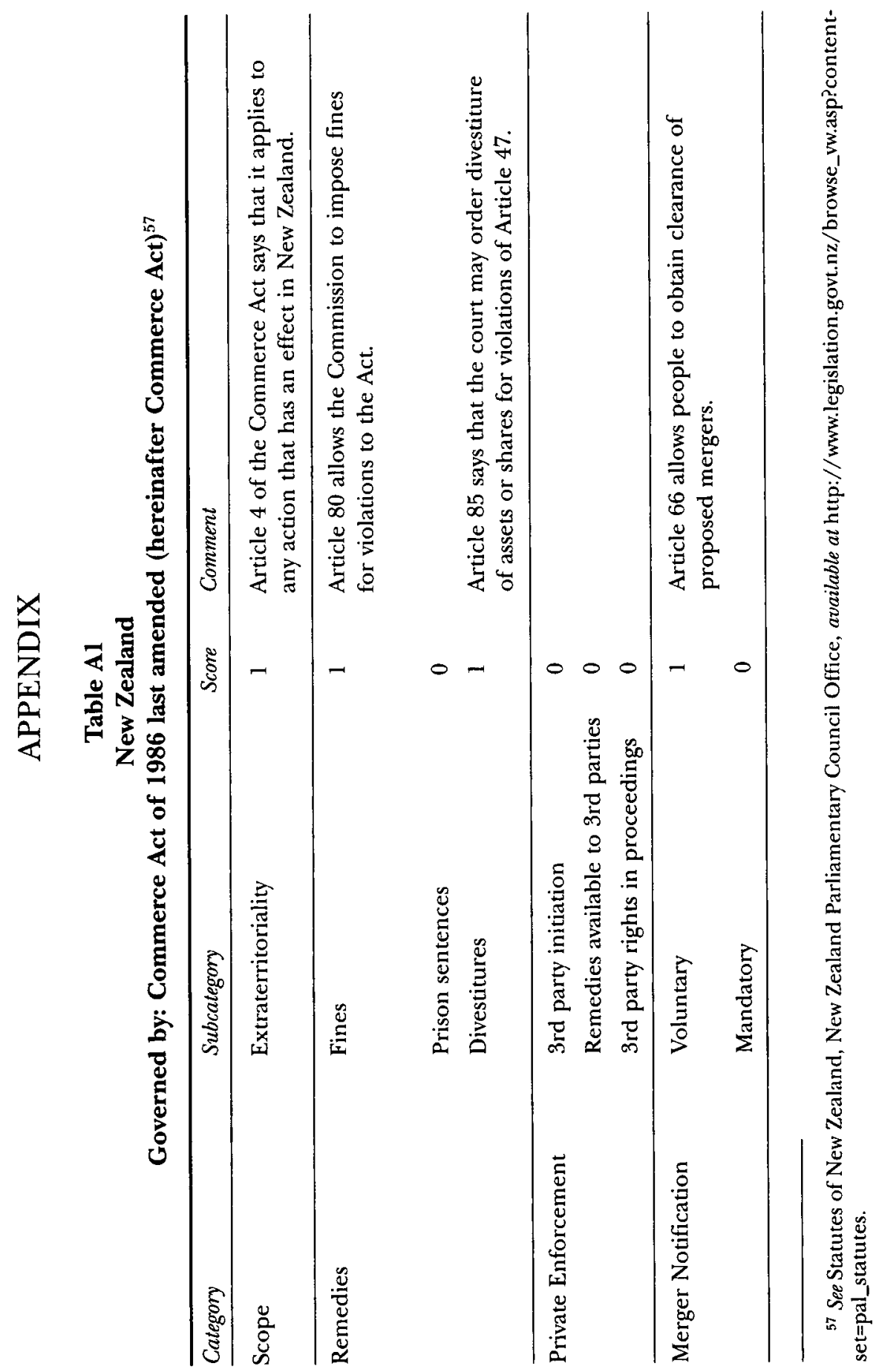




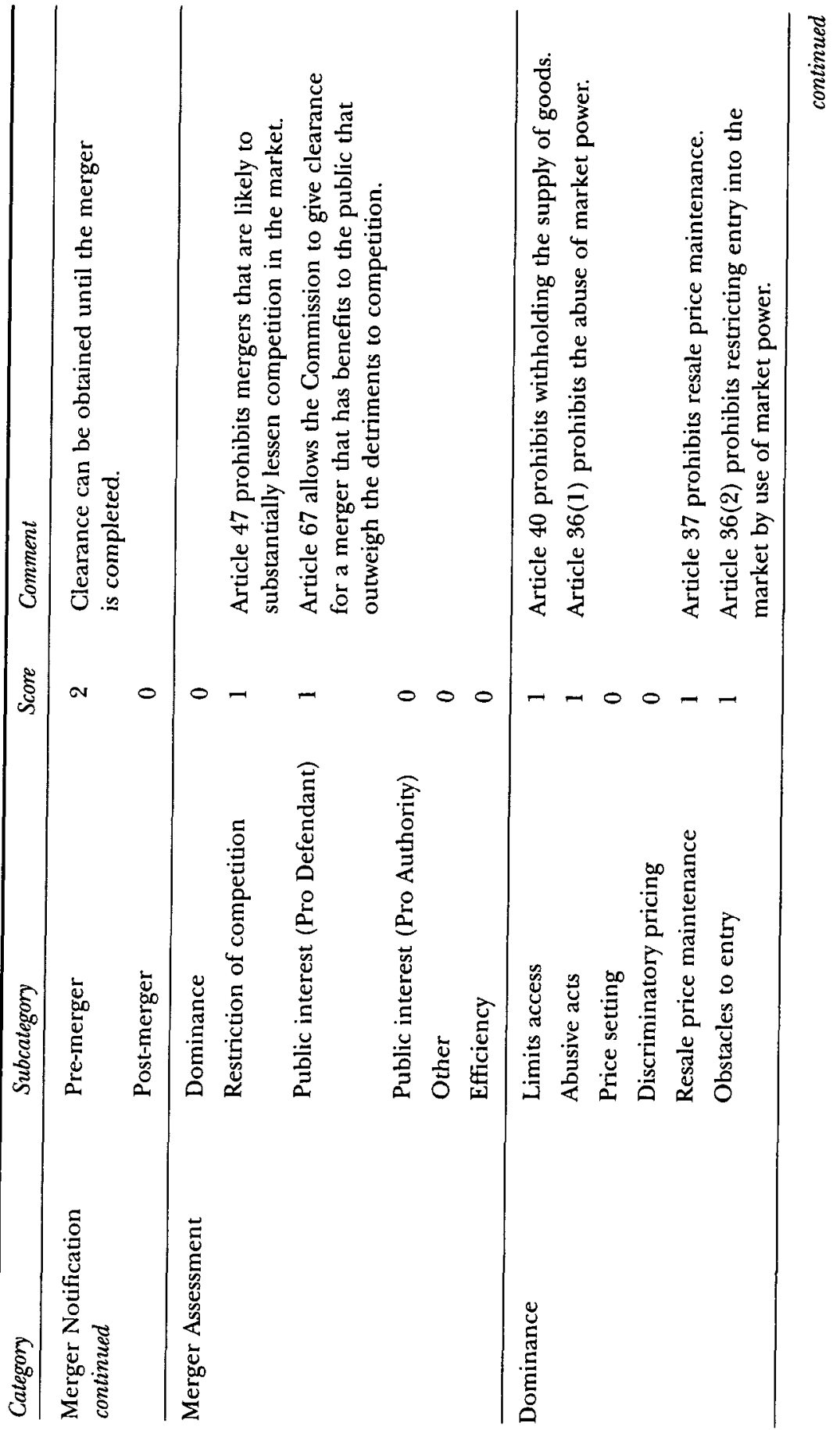




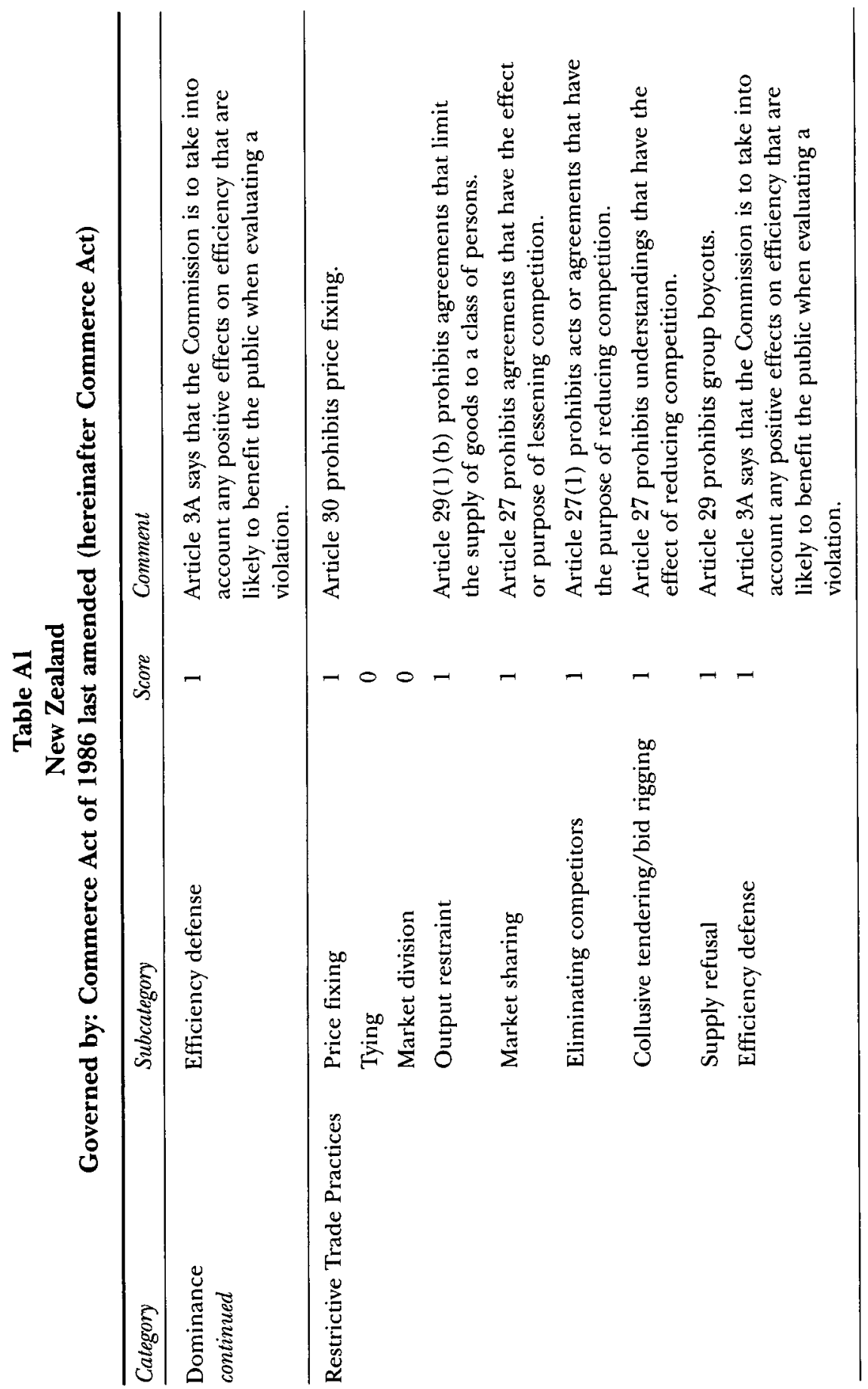




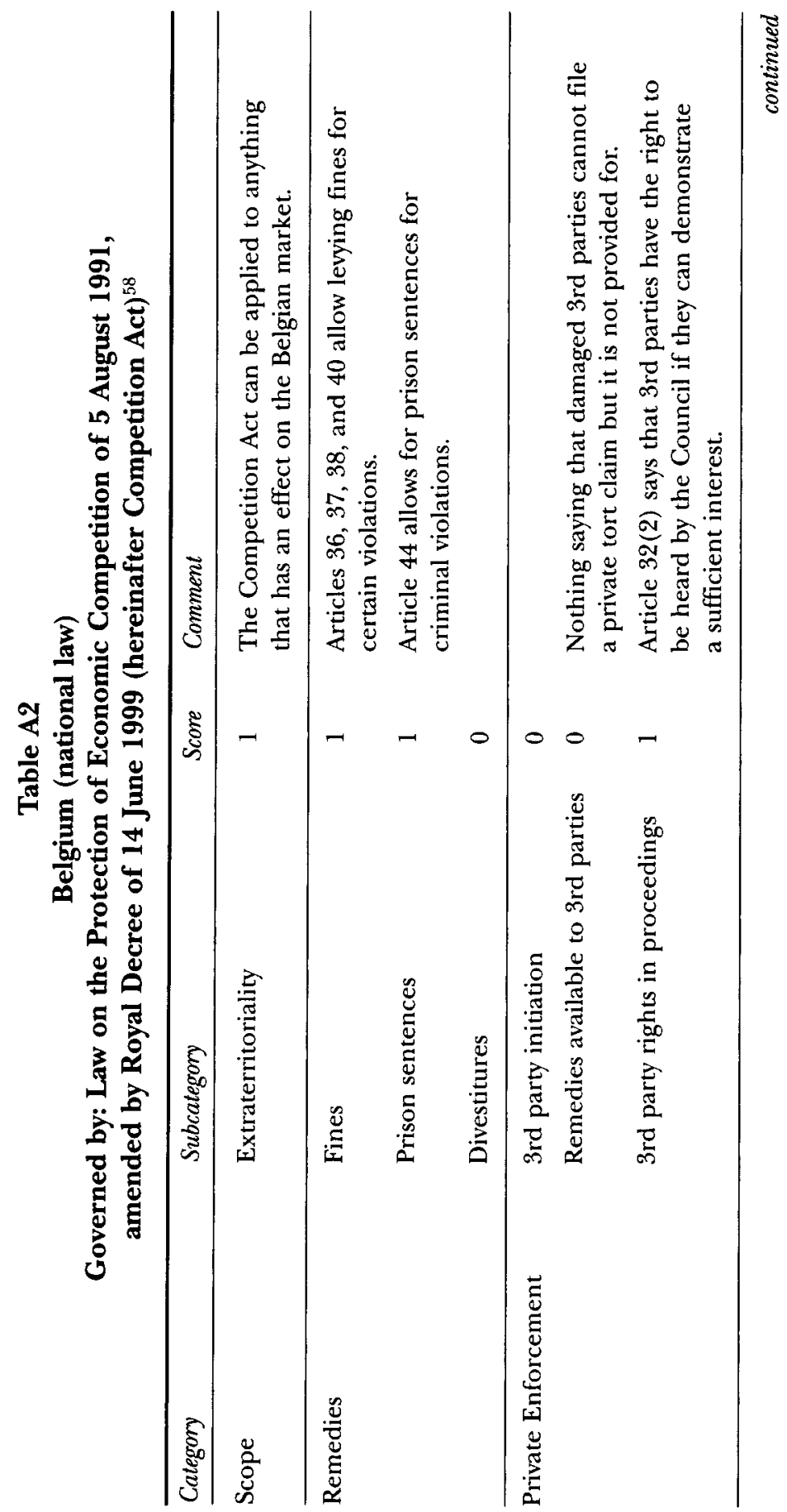




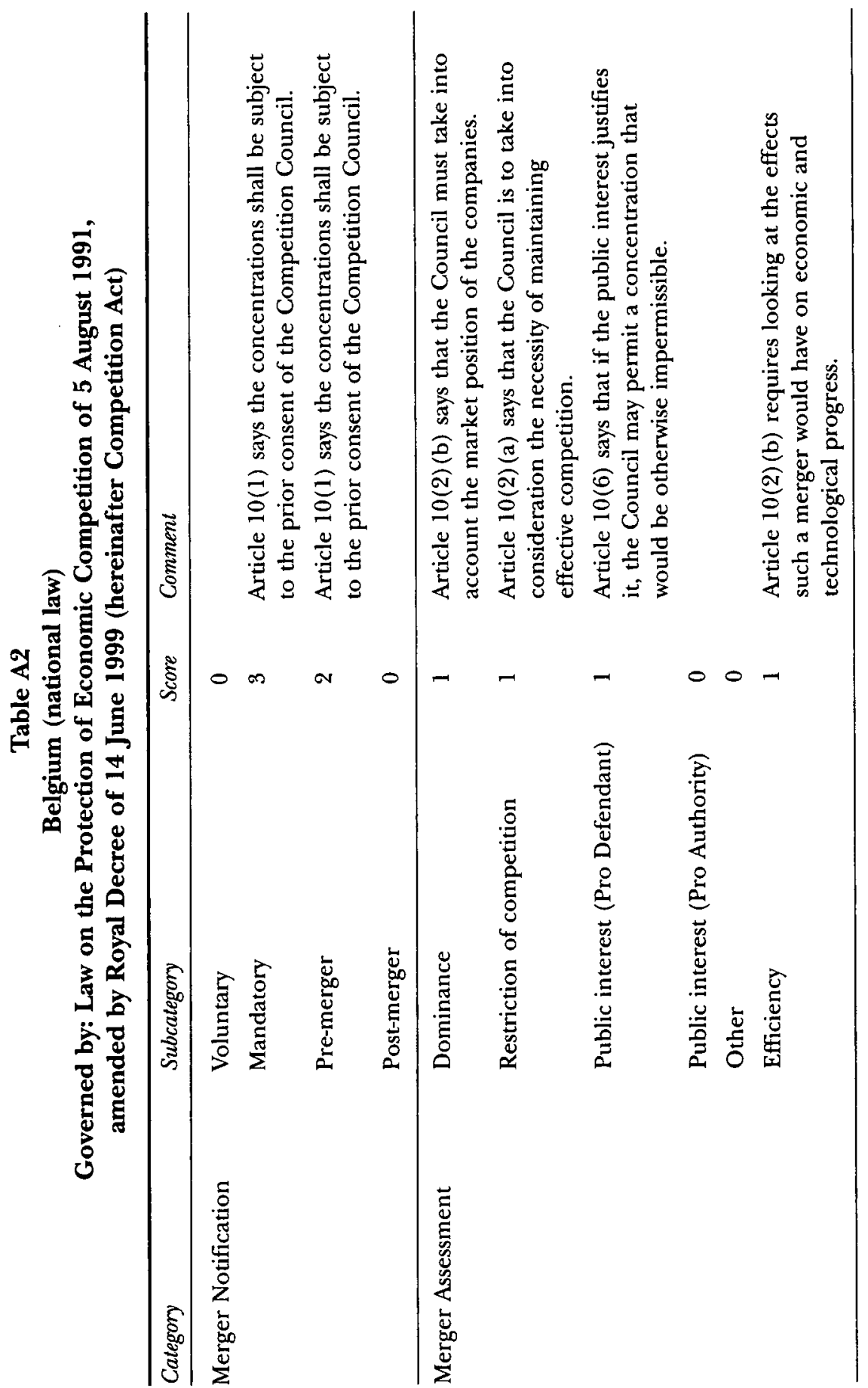




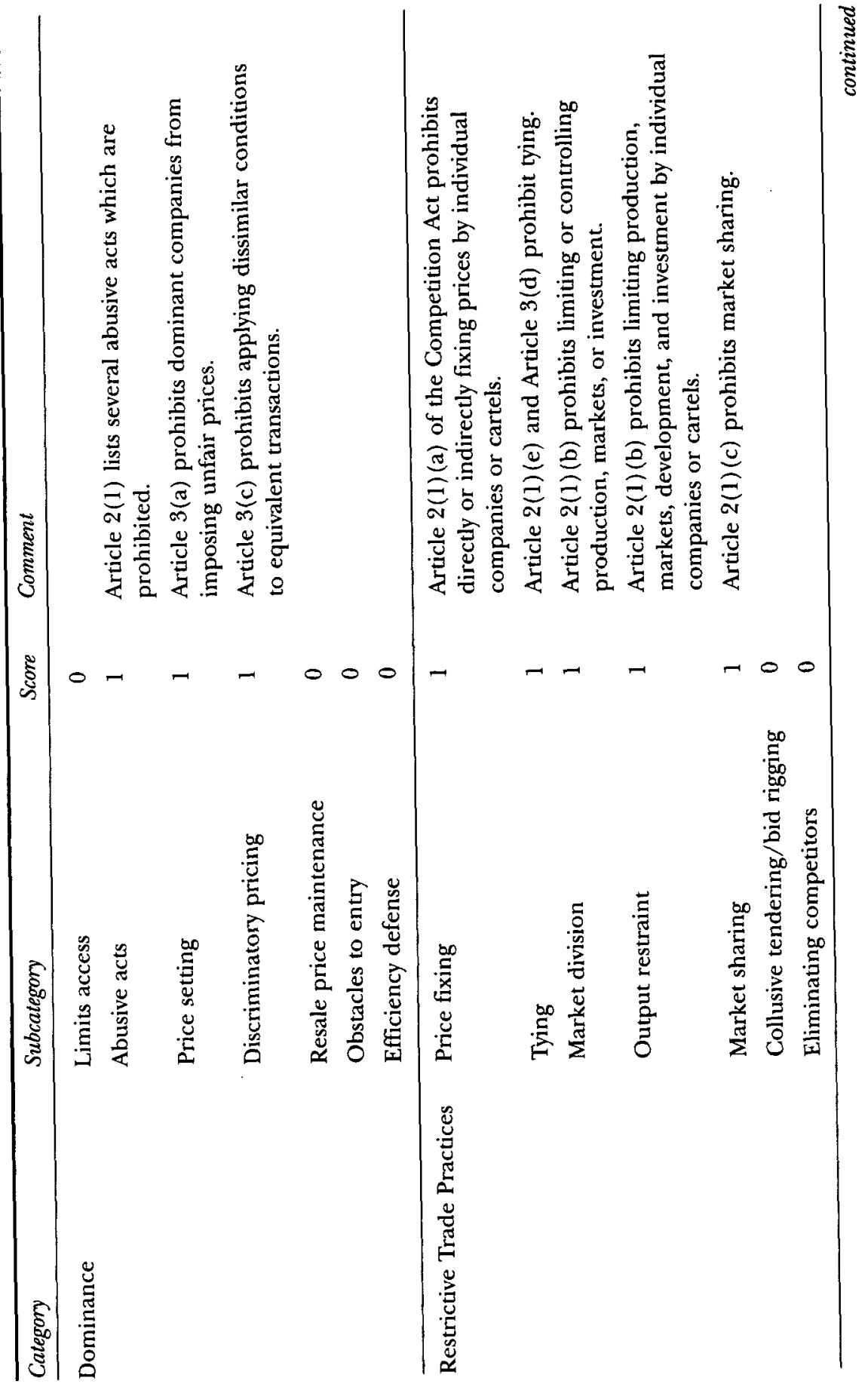




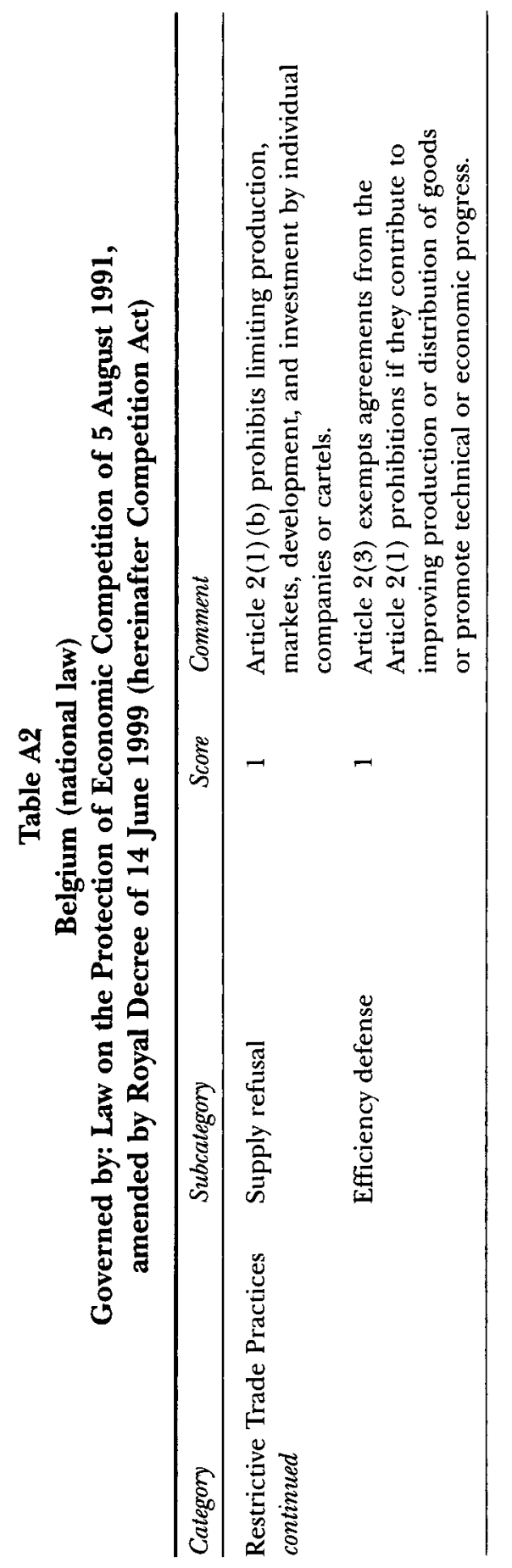




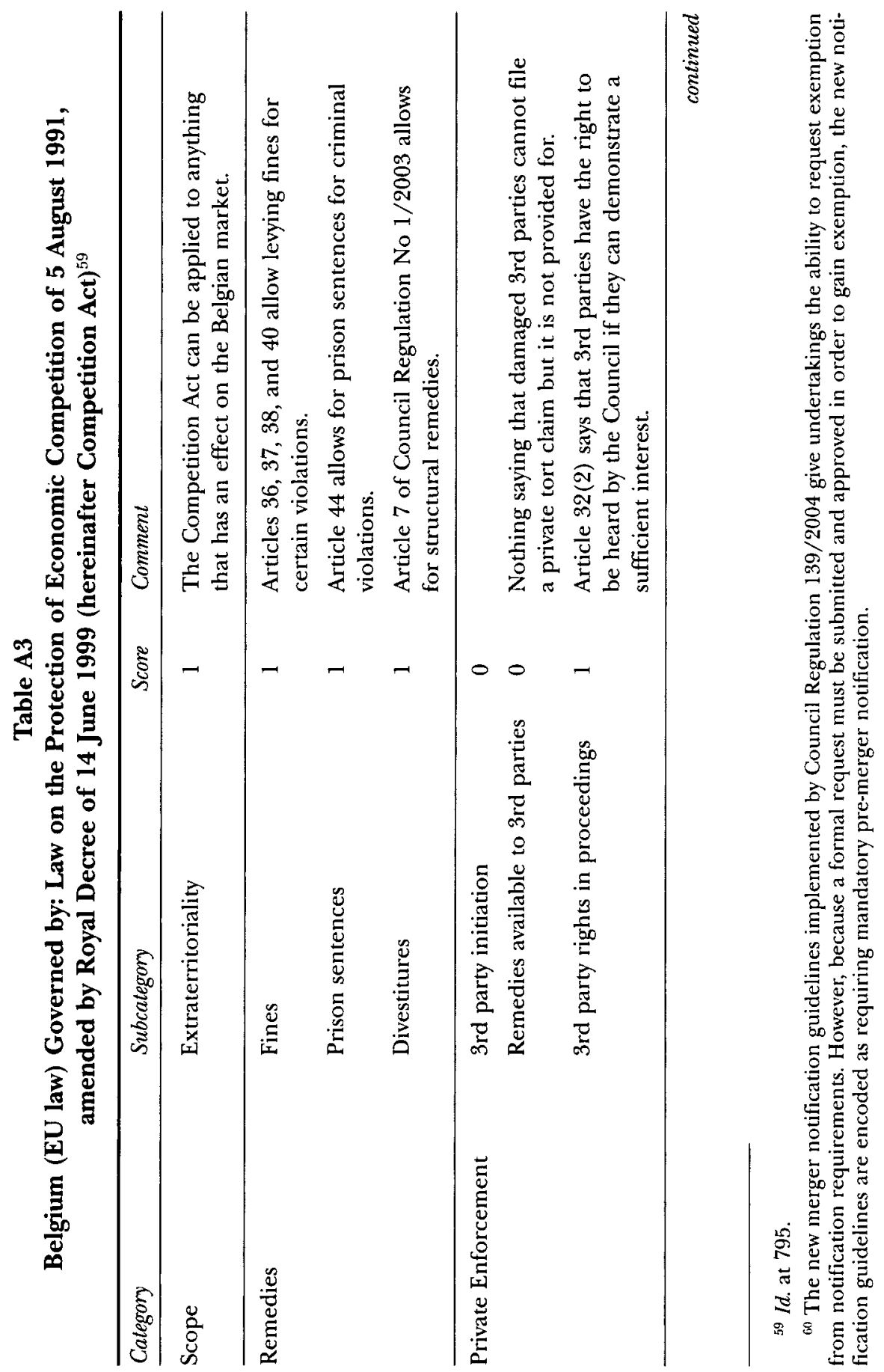




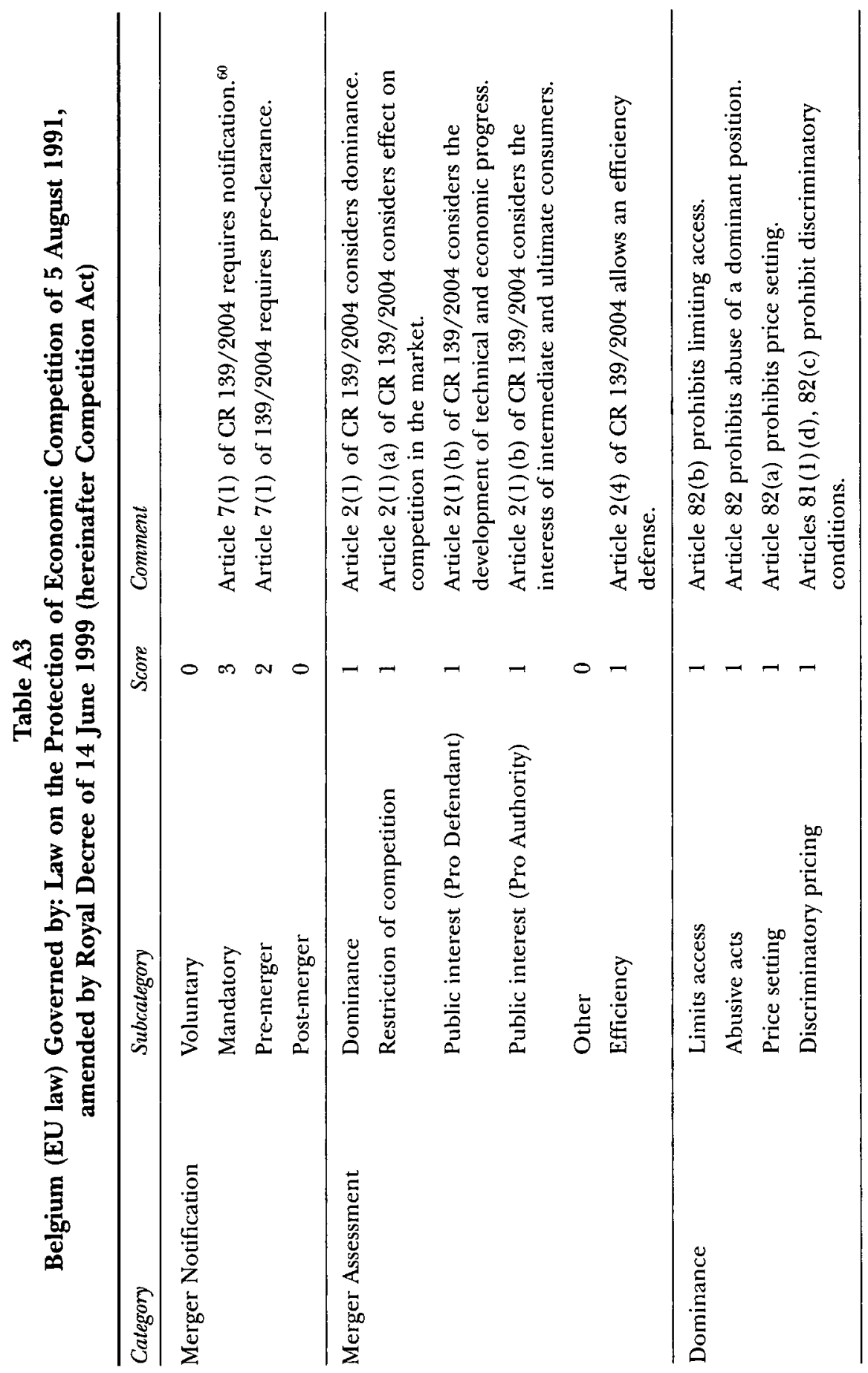



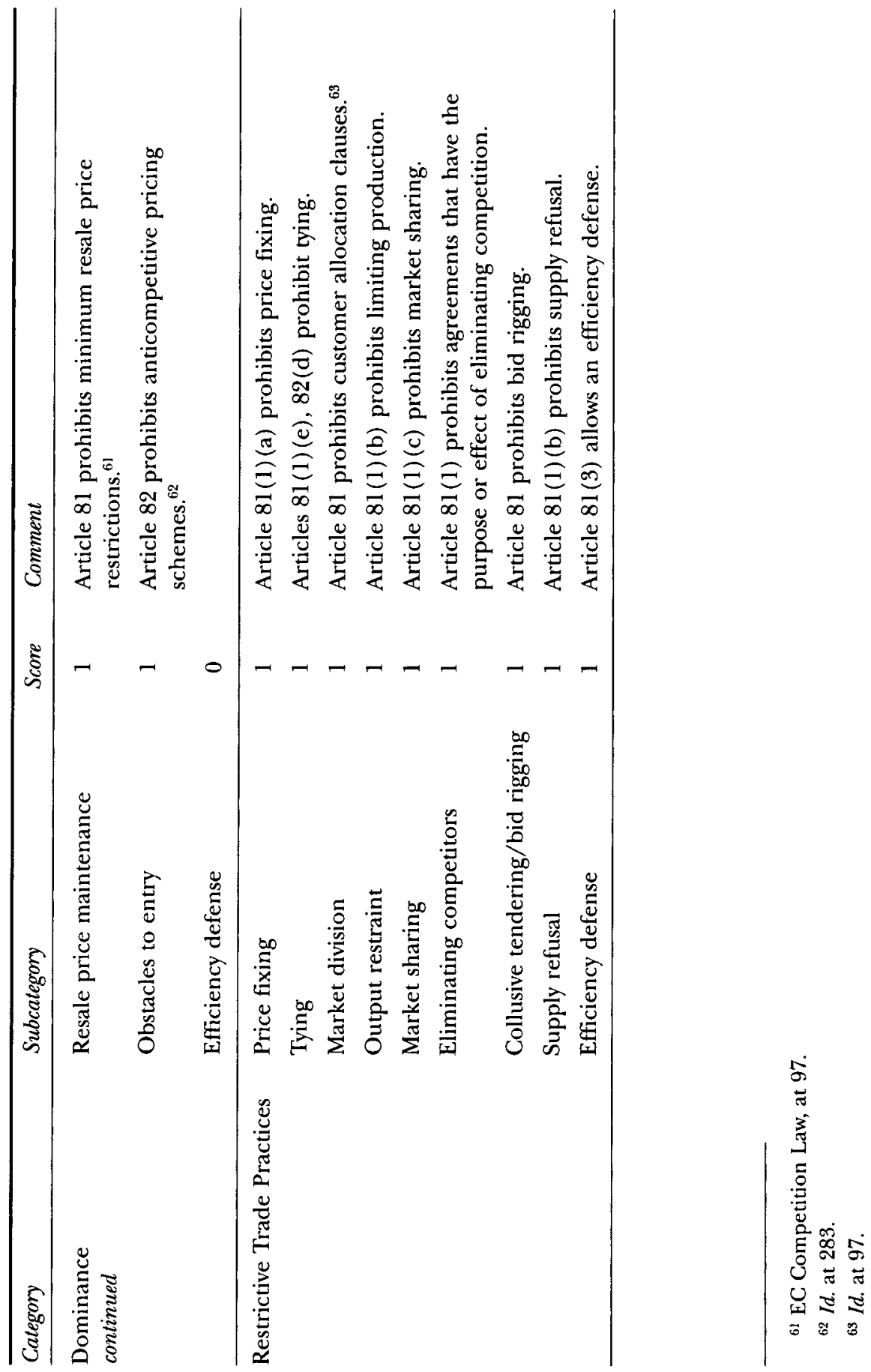


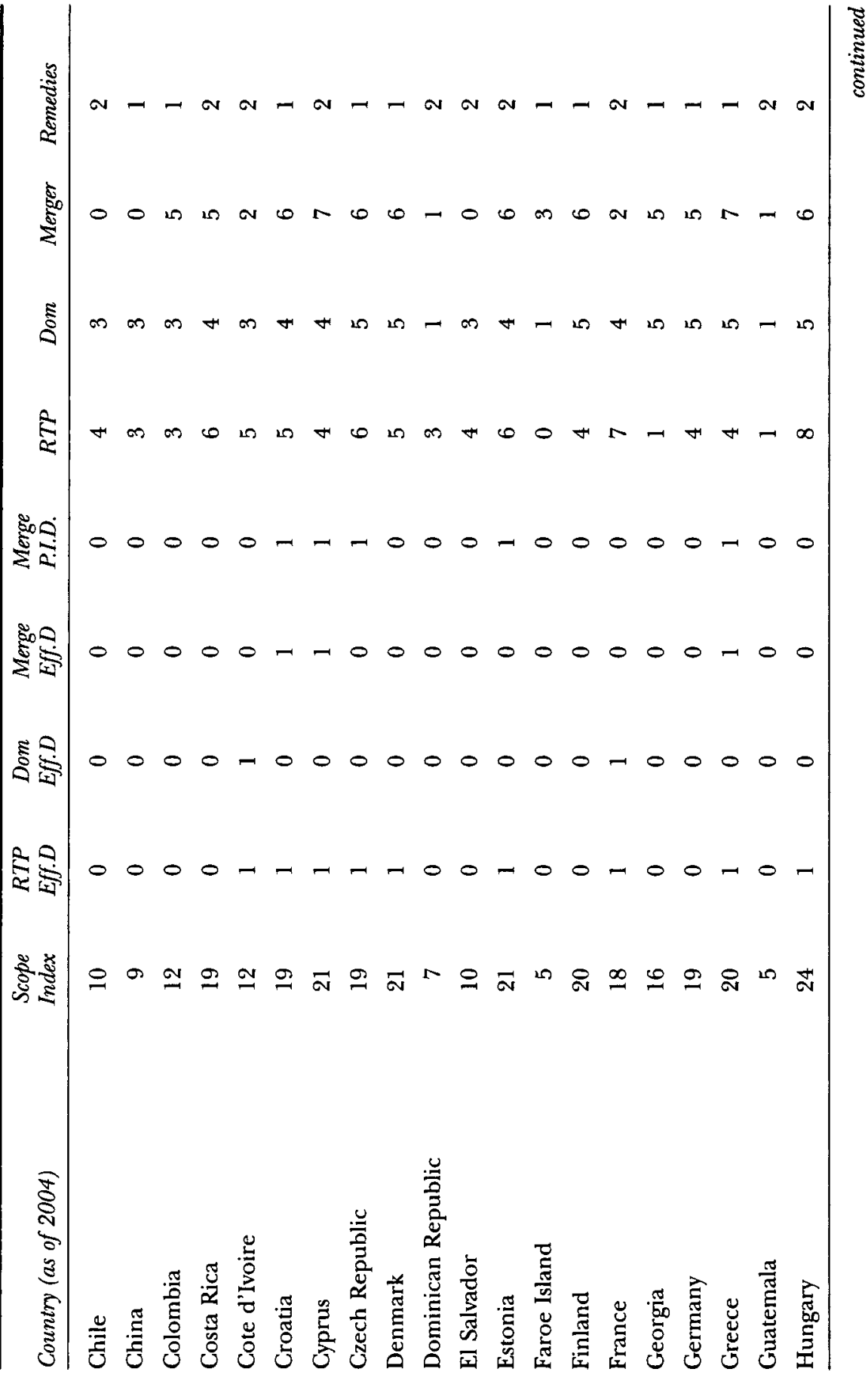




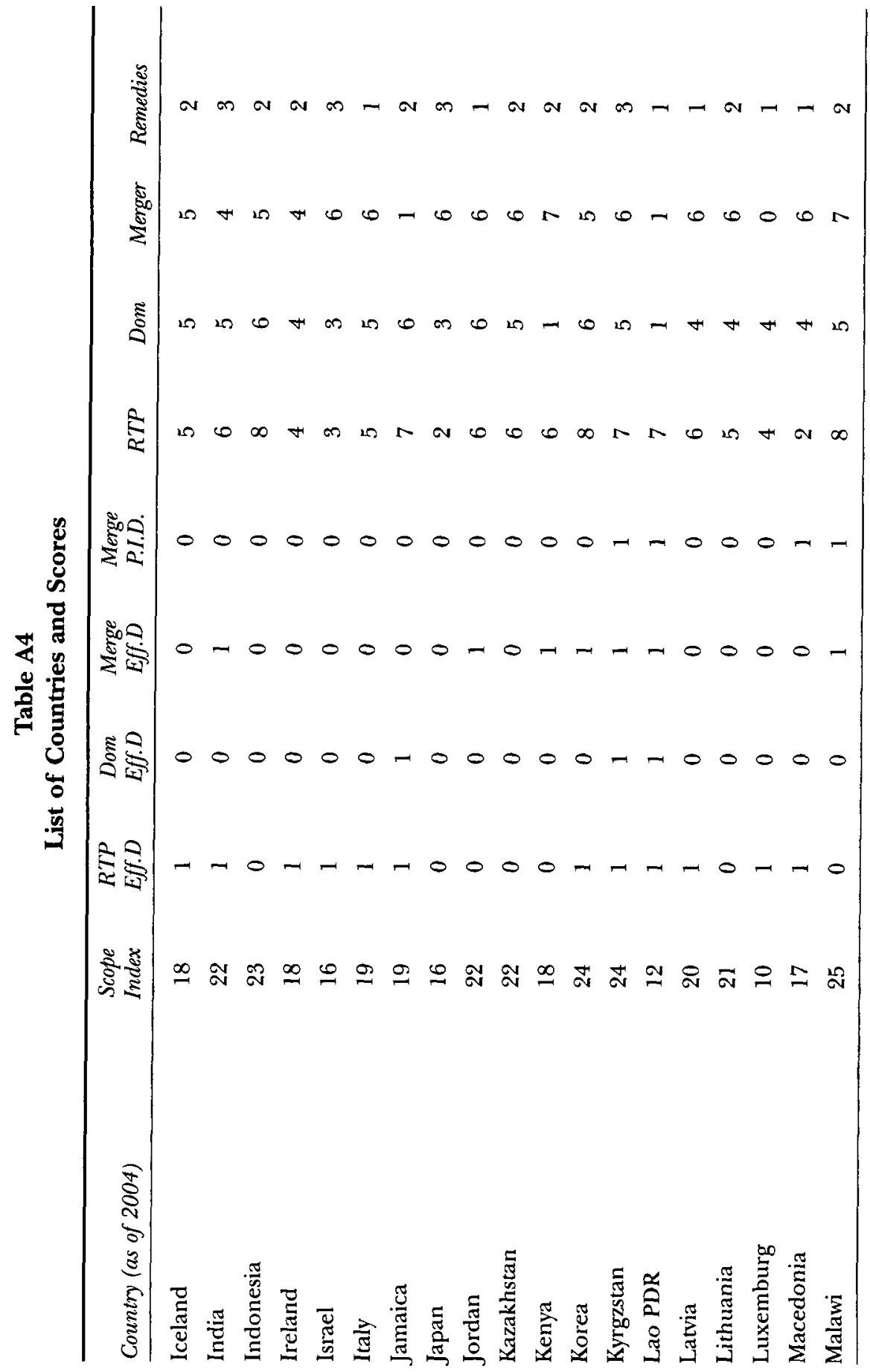




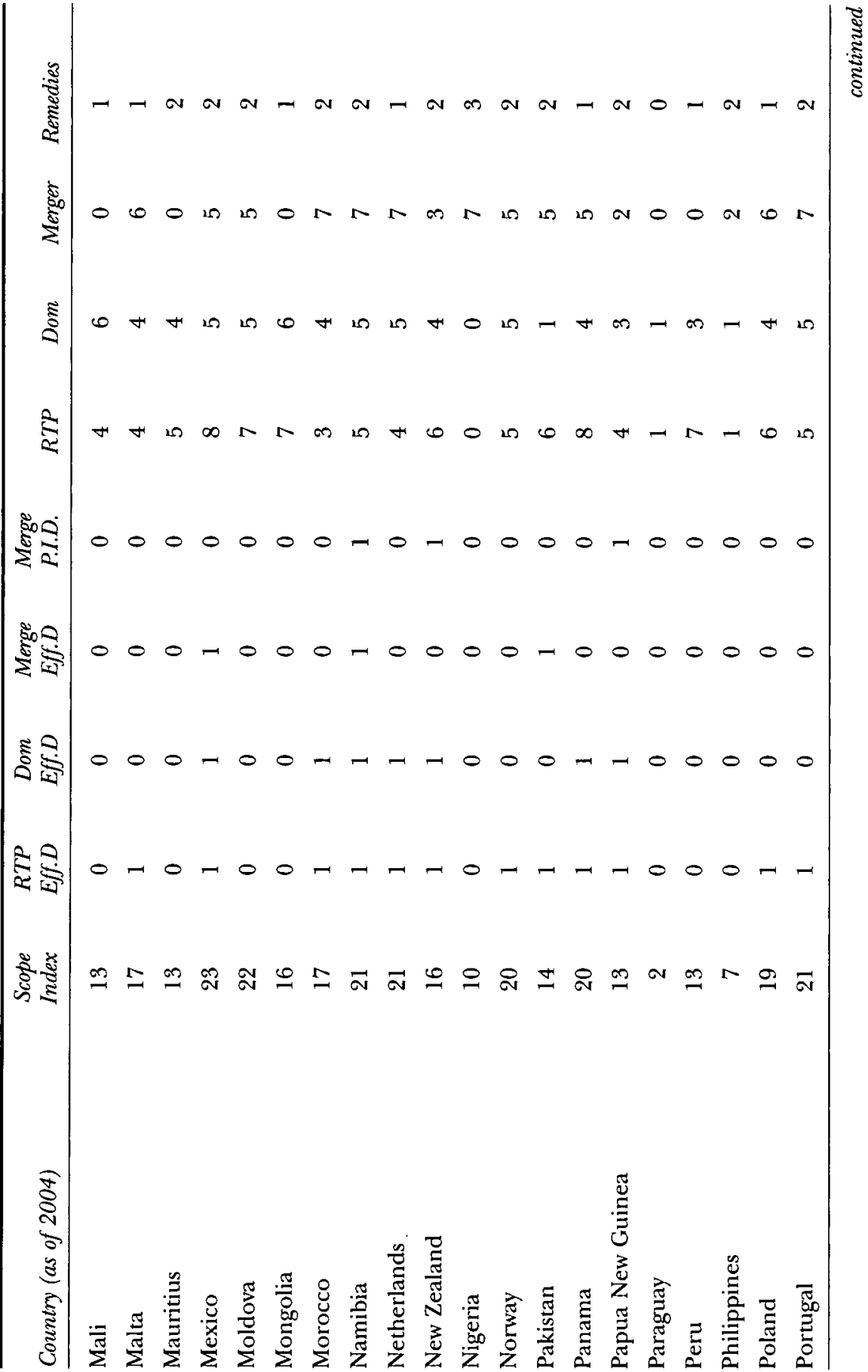




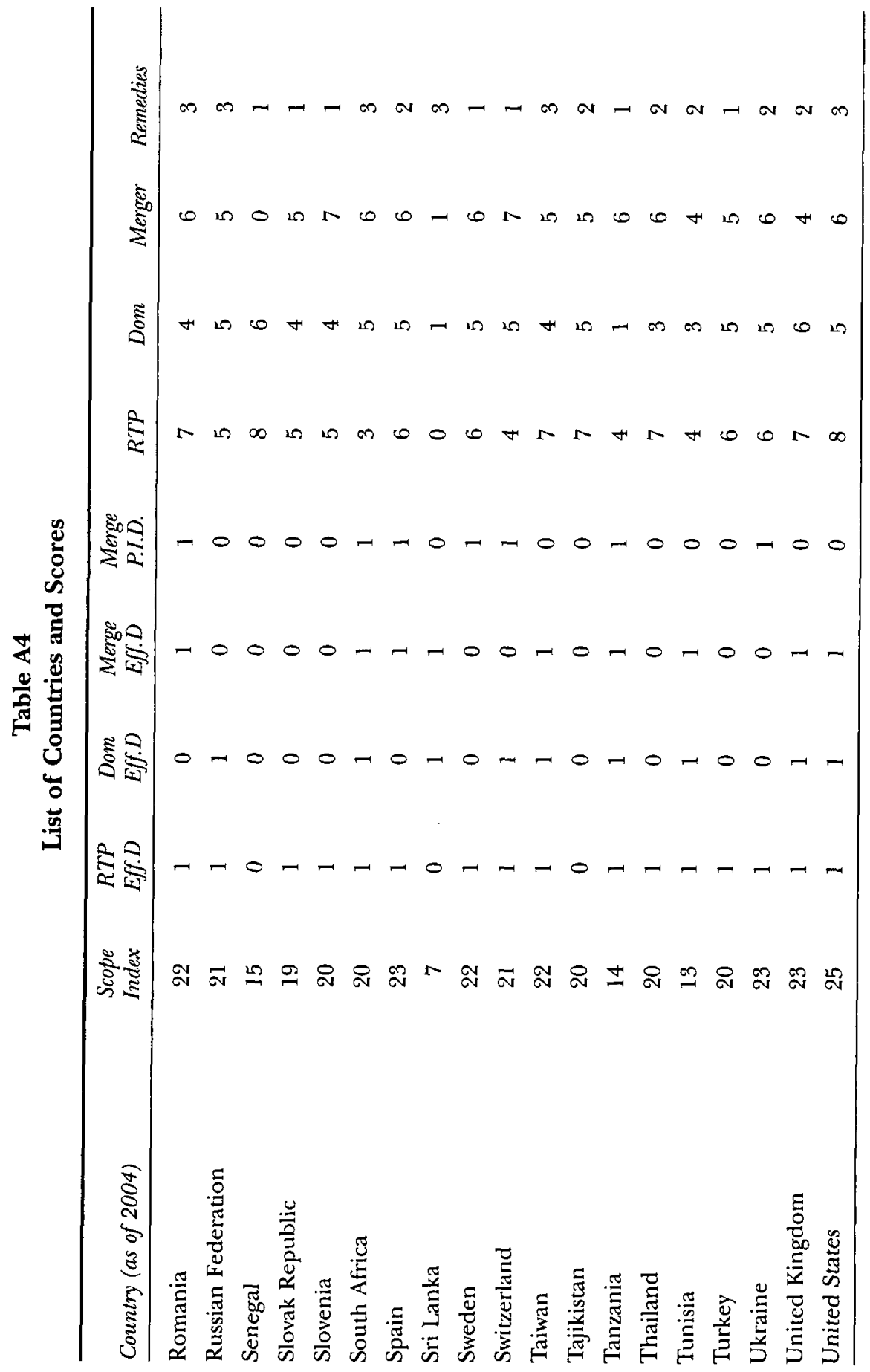




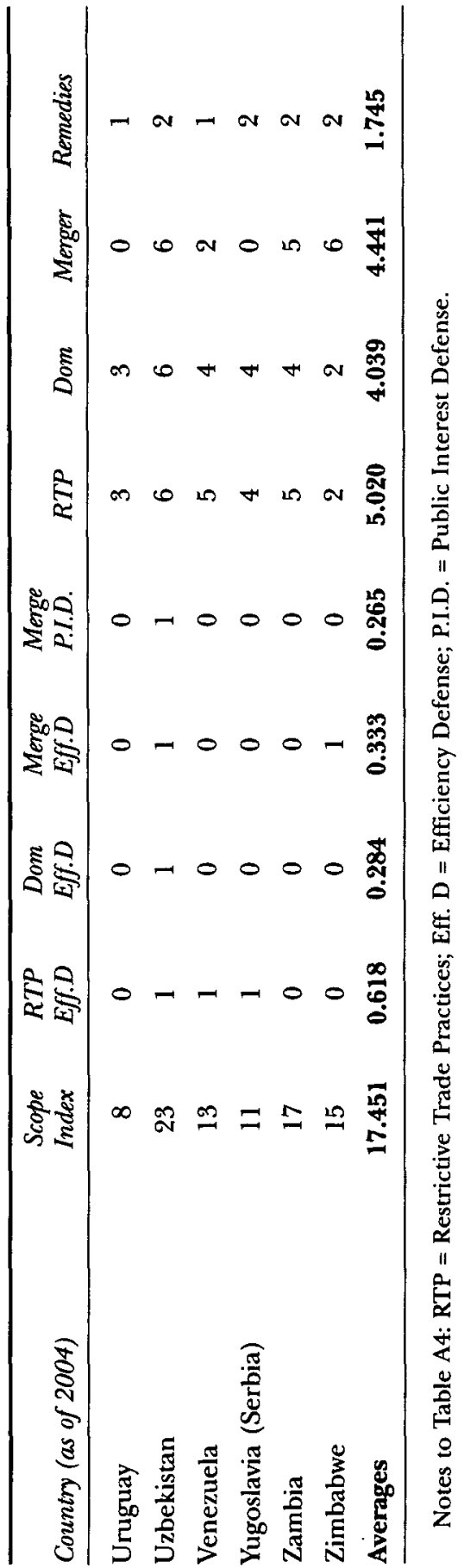




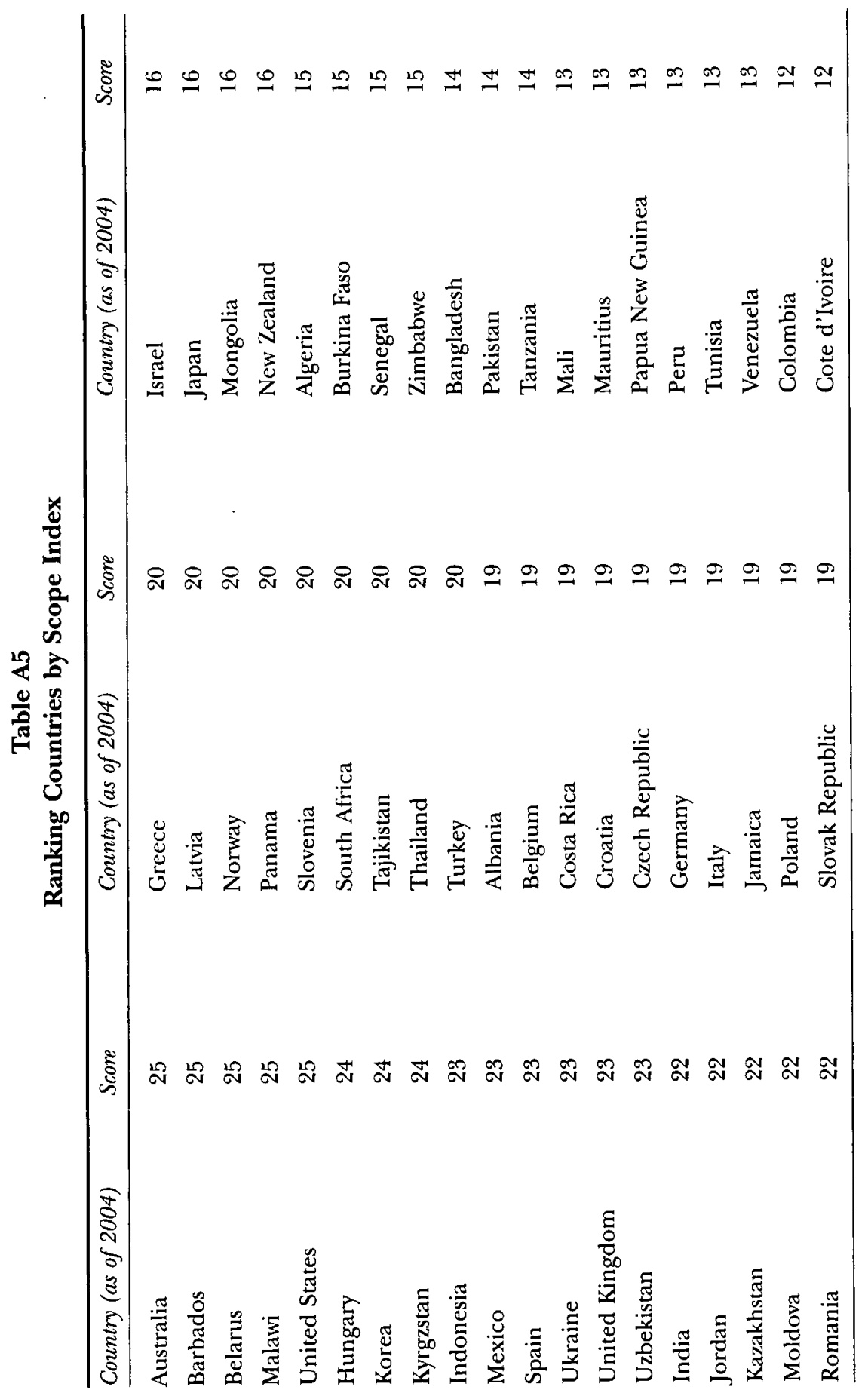




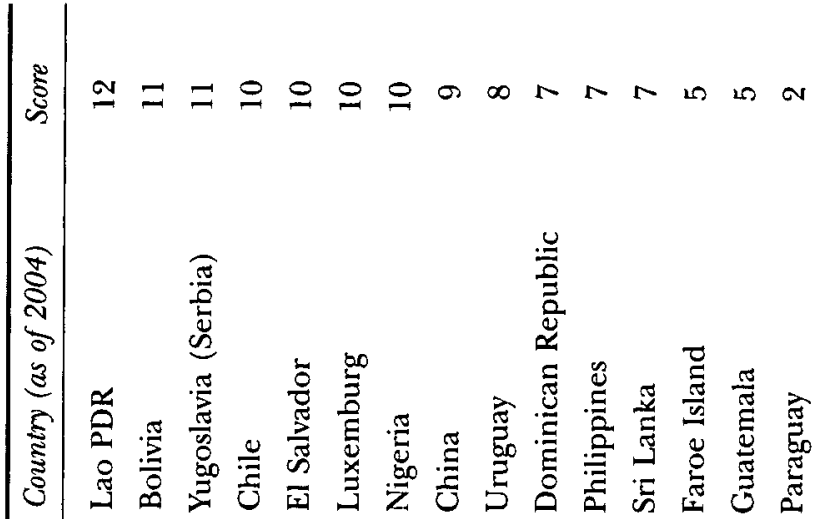

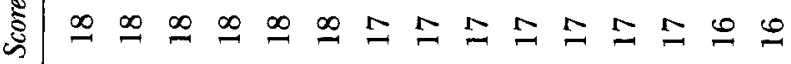

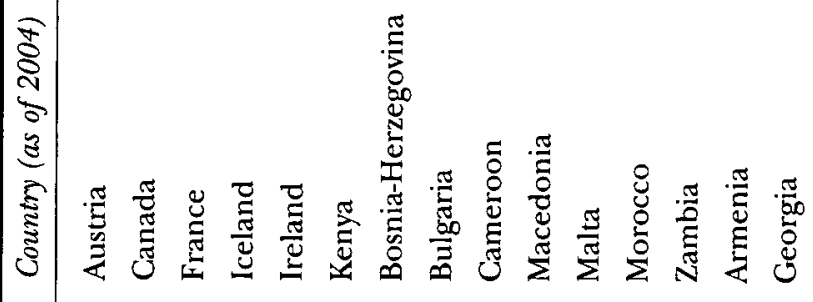

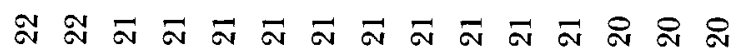

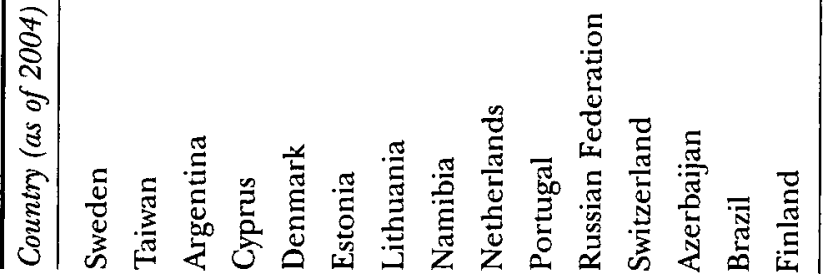




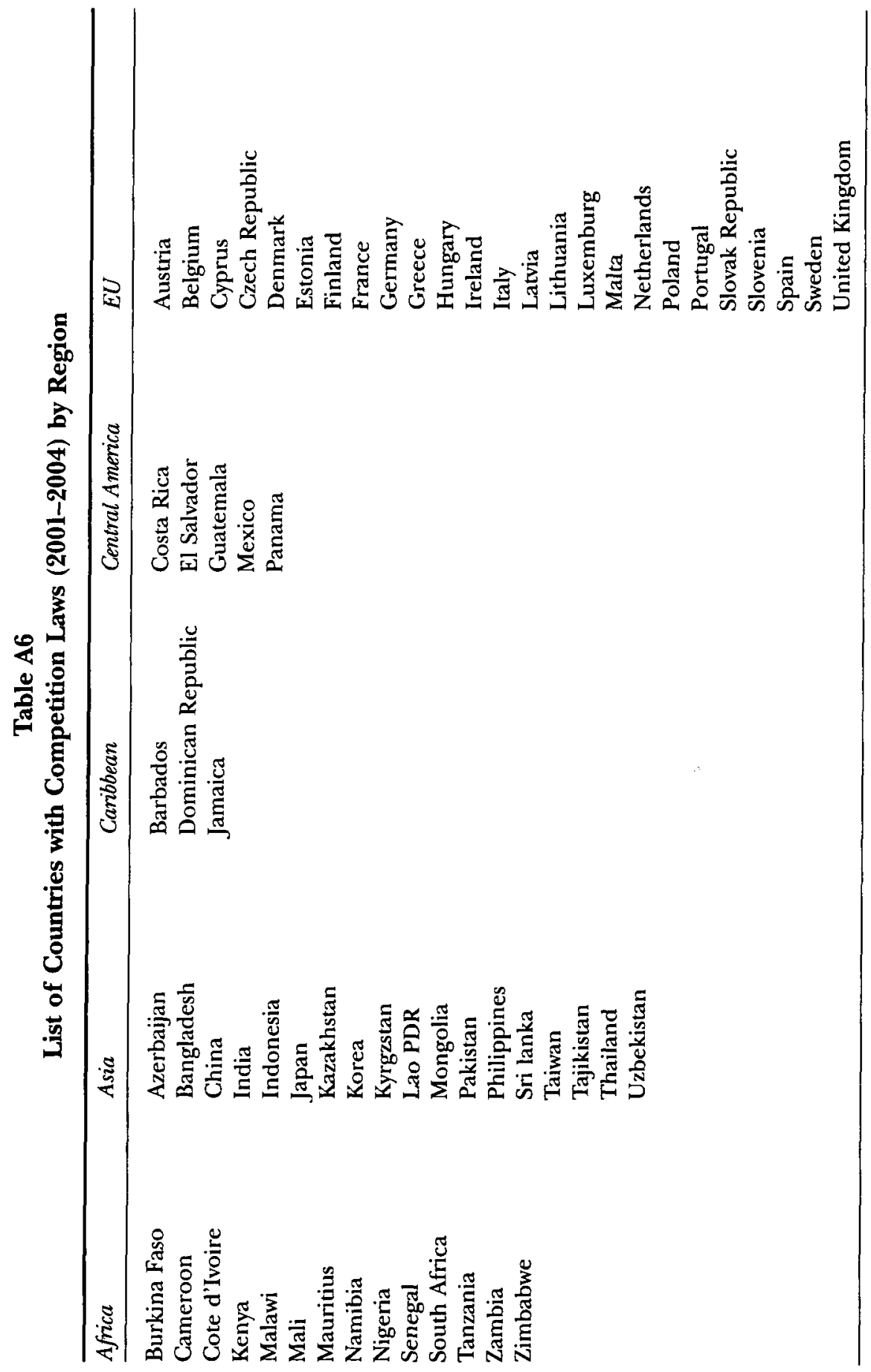




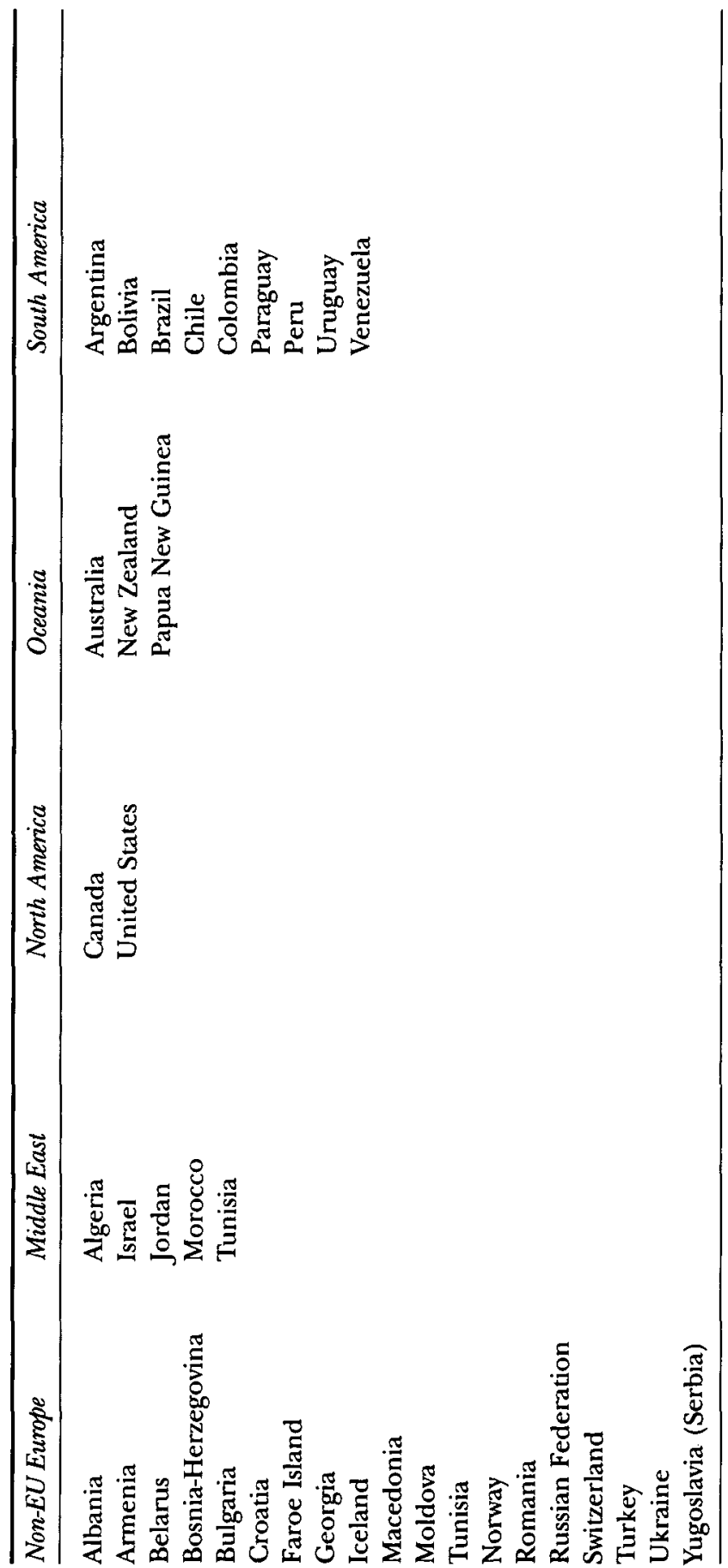




\section{APPENDIX: INDEX DEFINITIONS}

\section{Total Index Score (Minimum possible score 0-Maximum 30)}

The total index score is simply the sum of the scores for each category (e.g. scope, remedies, private enforcement, etc.). Defenses and pro-defendant elements do not contribute to the scores within each category and, likewise, do not contribute to the total index score.

\section{Scope (0-1)}

Extraterritoriality: The applicable law or act applies to foreign companies and citizens as long as the activity has some effect in the particular country. ${ }^{64}$

\section{Remedies (0-3)}

Fines: The law allows fines for violations of the applicable Act.

Prison Sentences: The law includes criminal violations that are punishable by imprisonment.

Divestitures: The law allows the selling of assets or division of the company in response to certain violations. ${ }^{65}$

\section{Private Enforcement (0-3)}

Third Party Initiation: Third parties (usually those damaged by the violations) can file private lawsuits or initiate an investigation or hearing by the applicable Commission or Council. ${ }^{66}$

${ }^{64}$ For example, "This Act shall also apply to all economic activities of [foreign companies], if their actions have a substantial effect on the market of Bosnia and Herzegovina ...." The Act on Competition, art. 2 (2005) (Bosn. \& Herz.), available at http:// www.bihkonk.gov.ba/en/laws/low_on_competition_new.pdf [hereinafter Bosnia Competition Act].

${ }^{65}$ For example, "[T] he [competition council] may require . . . the separation or divestiture of the merged undertakings or assets . . . in order to restore effective competition." Act LVII of 1996 on the Prohibition of Unfair and Restrictive Market Practices, art. 31 (2005) (Hung.), available at http://www.gvh.hu/data/pdf/jogi_hatter_mj_tpvt_ 2005nov1_a.pdf [hereinafter Hungary Competition Act].

${ }^{66}$ For example, "Any person who is aggrieved in consequence of any [prohibited practice] shall have a right of action under this subsection for relief ...." Competition Act $\S 6$ (2002) (Ir.), available at http://www.tca.ie/. 
Remedies Available to Third Parties: Remedies for damaged third parties are provided for in the Act. ${ }^{67}$

Third Party Rights in Proceedings: Third parties have access to evidence and/or can testify or otherwise participate in proceedings. ${ }^{68}$

\section{Merger Notification (0-5) ${ }^{69}$}

Voluntary: Companies are encouraged, but not required, to notify the applicable Commission or Council of an intended merger. ${ }^{70}$

Mandatory: Companies fitting particular criteria are required to notify the applicable Commission or Council of any intended merger. This gets a score of 3 if fulfilled in order to represent the comparative severity of a mandatory distinction as compared with a voluntary scheme. ${ }^{71}$

Pre-Merger: The Commission must be notified before the merger occurs (includes countries where the notification happens somewhat simultaneously with the merger). This gets a score of 2 if fulfilled. ${ }^{72}$

${ }^{67}$ For example, "A market participant who deliberately or by carelessness violates the provisions ... of this Law shall cover the losses which . . . have been caused to another market participant or party to a contract." Competition Law, $\$ 21$ (2001) (Lat.), available at http://www.competition.lv/uploaded_files/ENG/E_likumK.pdf.

${ }^{68}$ For example, "Persons who participate in a case shall have the right: to familiarize themselves with the materials of the case ...; to provide evidence, to submit applications, verbal and written explanations ..." Law of Ukraine on the Protection of Economic Competition, arts. 39-40 (2001) (Ukr.), available at http://www.globalcompetitionforum.org/ regions/europe/Ukraine/LEGISLATION.pdf.

${ }^{69}$ The scoring in this area breaks from a basic dummy variable scheme in order to preserve accurate ordering of the relative severity of different Merger Notification regimes. Under this scoring scheme, a Mandatory Pre-Merger regime receives a 5, a Mandatory Post-Merger regime receives a 4, a Voluntary Pre-Merger regime receives a 3, a Voluntary Post-Merger regime receives a 2, a Voluntary regime that makes no mention of a time requirement is assumed to be "Post-Merger" and therefore receives a 2, and a regime that makes no mention of a notification requirement receives a 0 . For construction of the Scope Index, each score was reduced by 1.

${ }^{70}$ For example, "[A]ny person or enterprise, who or which proposes to enter into a combination, may, at his or its option, give notice to the commission . . . disclosing the details of the proposed combination[.]" The Competition Act, art. 6(2) (2002) (India), available at http://www.competition-commission-india.nic.in/Act/competition_act2002. pdf.

${ }^{71}$ For example, "Where a merger is proposed each of the undertakings involved must notify the Commission of the proposal in the prescribed manner." Competition Act, No. 92, art. 44(1) (2003) (Namib.), available at http://www.globalcompetitionforum.org/ regions/africa/Namibia/ACT511.pdf [hereinafter Namibia Competition Act].

${ }^{72}$ For example, "A business operator shall not carry out a business merger . . . unless the Commission's consent is obtained." Competition Act, B.E. 2542, $\$ 26$ (1999) (Thail.), available at http://www.globalcompetitionforum.org/regions/asia/Bangkok/Bankok\% 20 Act.pdf. 
Post-Merger: The Commission is notified after the merger (and then often has the power to invalidate the completed merger)..$^{73}$

\section{Merger Assessment (0-4)}

Dominance: The Commission or Council takes into consideration the dominant position or market share that the company will have if the merger occurs. $^{74}$

Restriction of Competition: The Commission or Council considers the merger in light of maintaining effective competition, the potential effects on the structure of the market, and possible barriers to entry. ${ }^{75}$

Public Interest (Pro D): The Commission or Council considers whether an otherwise impermissible merger may be allowed because it is in the public interest and/or will have benefits or advantages to the consumers. ${ }^{76}$

Public Interest (Pro Authority): The Commission or Council has the power to prohibit a merger if it is concerned it runs contrary to public interests such as national security. ${ }^{77}$

${ }^{73}$ For example, "A party to a [regulated] merger shall notify the Commission of the proposed merger within 30 days of the conclusion of the merger agreement between the merging parties; or the acquisition by any one of the parties to that merger of a controlling interest in another." Zimbabwe Amended Competition Act, art. 12 (2001) (Zimb.), available at http://www.globalcompetitionforum.org/regions/africa/Zimbabwe/ Competition\%20Amendment\%20Act.pdf.

${ }^{74}$ For example, "A concentration which creates or strengthens a dominant position in the affected markets ... shall be declared [illegal]." Law to Provide for the Control of Concentrations between Enterprises for the Purposes of Protection of Effective Competition, No. 22(1), art. 10 (1999) (Cyprus), available at http://www.competition.gov.cy/ competition/competition.nsf/All/5790CF902F3E4AA5C2256F01003CF9A7/\$file/ concentration.pdf?OpenElement [hereinafter Cyprus Competition Law].

${ }^{75}$ For example, "The Authority may refuse to approve a merger or acquisition if it is satisfied that the merger or acquisition would substantially lessen competition in Jersey or any part of Jersey." Competition (Jersey) Law 2005, art. 22(4), available at http:// www.jcra.je/pdf/051101\%20Competition-Jersey-Law-2005.pdf.

${ }^{76}$ For example, "[A decision to make a certain practice illegal] may not be applied to ... concentrations that contribute to the improvement of production or distribution of goods and services or the promotion of technical or economic progress [while] allowing consumers a fair share of the resulting benefit ...." Bosnia Competition Act, art. 7.

${ }^{77}$ For example, "The Commission shall declare a concentration as compatible or incompatible with the requirements of the competitive market after taking into account ... the interests of intermediate and final consumers ...." Cyprus Competition Law, art. 12. 
Other: The Commission or Council considers other issues, such as international competitiveness, effects on employment markets, and promoting minority ownership. ${ }^{78}$

Efficiency Defense: The Commission or Council may allow an otherwise impermissible merger if it will contribute sufficiently to economic efficiency. $^{79}$

\section{Dominance (0-6)}

Limits Access: A single dominant firm may not limit the supply of goods to the market or in other ways restrict access to the market by consumers or competitors. ${ }^{80}$

Abusive Acts: The Act lists or otherwise indicates acts that would constitute an impermissible abuse of a dominant position. ${ }^{81}$

Price Setting: It is impermissible for a single firm to arbitrarily or unfairly set the price of a good by taking advantage of its dominant position. ${ }^{82}$

Discriminatory Pricing: A single dominant firm may not impose different prices for the same goods or services for different customers. ${ }^{83}$

Resale Price Maintenance: The Act does not allow single firms to set the price at which its customers will ultimately sell their product to consumers. ${ }^{84}$

${ }^{78}$ For example, "The Commission may base its determination of a proposed merger on any criteria which it considers relevant [including] the extent to which the proposed merger would be likely to affect the ability of small undertakings, in particular small undertakings owned or controlled by historically disadvantaged persons, to gain access to or to be competitive in any market[.]" Namibia Competition Act, art. 47(2)(f).

${ }^{79}$ For example, "[The Commission may consider] any benefits likely to be derived from the proposed merger relating to research and development, technical efficiency, increased production, efficient distribution of goods or provision of services and access to markets." Id. art. 47(2)(h).

${ }^{80}$ For example, "It shall be prohibited . . . to limit production, distribution or technical development to the prejudice of consumers[.]" Hungary Competition Act, art. 21.

${ }^{81}$ For example, "It shall be prohibited to abuse a dominant position ... ." Id.

${ }^{82}$ For example, "It shall be prohibited . . . to set unfair purchase or selling prices ...."Id.

${ }^{83}$ For example, "It shall be prohibited . . . in the case of transactions which are equivalent in terms of their value or character to discriminate, without justification, against trading parties including in relation to the application of prices, periods of payment, [etc.]" Id.

${ }^{84}$ For example, "[Illegal acts include] any agreement, decision, or concerted practice which ... involves a practice of minimum resale price maintenance[.]" Namibia Competition Act, art. 23(3)(d). 
Obstacles to Entry: A dominant firm is prohibited from imposing various restrictions or coercive practices that make it very difficult for competitors to enter the market or increase their market share. ${ }^{85}$

Efficiency Defense: An otherwise impermissible act is excused if it substantially contributes to economic efficiency or to the public good. ${ }^{86}$

\section{Restrictive Trade Practices (0-8)}

Price Fixing: A cartel or group of companies is not allowed to attempt to set the price for their product in the market. ${ }^{87}$

Tying: A group of companies is not allowed to condition contracts on buying additional products that are not directly connected to the product that is the subject of the contract. ${ }^{88}$

Market Division: A group of companies cannot agree to divide or allocate the market by a particular geographic, demographic, price-defined, or otherwise-defined characteristic..$^{89}$

Output Restraint: A group of companies is not allowed to agree to limit the overall rate of production or amount of products made available to the market. ${ }^{90}$

${ }^{85}$ For example, "[A dominant Enterprise] is prohibited from abusing this Dominant Position in order to prevent, limit, or weaken competition including ... [performing an] activity or action which leads to setting barriers of entry of other Enterprises to the market ... ." The Competition Law, No. 33, art. 6(b) (2004) (Jordan), available at http:// www.internationalcompetitionnetwork.org/media/archive $0611 /$ mergerjordanlaw.pdf.

${ }^{86}$ For example, "The Commission may . . . grant an exemption for [an] agreement [if] . . . the agreement results or is likely to result in benefits to the public [such as] by contributing to greater efficiency in production or distribution; by promoting technical or economic progress [etc.]" The Fair Competition Act, art. 12 (2003) (Tanz.), available at http://www.parliament.go.tz/Polis/PAMS/Docs/8-2003-2003.pdf.

${ }^{87}$ For example, "[Agreements involving] the direct or indirect fixing of purchase or selling prices or other business terms and conditions [are prohibited.]" Hungary Competition Act, art. 11.

${ }^{88}$ For example, "[M]aking the conclusion of contracts subject to the acceptance of obligations which, by their nature or according to commercial usage do not belong to the subject of such contracts [is prohibited.]" Id.

${ }^{89}$ For example, "Prohibited are all agreements between economic subjects, associations and concerted practices relating to ... the division of markets or sources of supply of goods and services [.]" Bosnia Competition Act, art. 4(c).

${ }^{90}$ For example, "Agreements or concerted practices [relating to] the limitation or control of production, distribution, technical development or investment [are prohibited.]" Hungary Competition Act, art. 21. 
Market Sharing: A group of companies cannot agree to share a certain market by not competing with each other for business or customers. ${ }^{91}$

Eliminating Competitors: The law prohibits acts by a group of companies that have the purpose and/or effect of reducing the amount of competition in the market. ${ }^{92}$

Collusive Tendering/Bid Rigging: It is illegal for a group of firms to agree not to bid at market price for a certain product in order to manipulate the market price of that product. ${ }^{93}$

Supply Refusal: A group of companies cannot agree not to sell their products to certain other companies or groups of companies for arbitrary reasons. ${ }^{94}$

Efficiency Defense: An otherwise impermissible practice may be allowed if it contributes significantly to economic efficiency or to the public good. ${ }^{95}$

${ }^{91}$ For example, "Agreements or concerted practices [relating to] the allocation of markets, exclusion from sales, or restriction of the choice of marketing possibilities [are prohibited.]" Id.

${ }_{92}$ For example, "Agreements or concerted practices between undertakings . . which have as their object or potential or actual effect the prevention, restriction, or distortion of competition, shall be prohibited." Id.

${ }^{93}$ For example, "[T] he collusion of competitors during the bidding process [is prohibited]." Id. art. 21.

${ }^{94}$ For example, "[C]oncerted refusals to supply goods or services to potential purchasers [are prohibited.]" Malawi Competition and Fair Trading Bill, § 33(3) (f) (1998) (Malawi), available at http://r0.unctad.org/en/subsites/cpolicy/Laws/malawi.pdf.

${ }^{95}$ See supra note 25. 
